\title{
La consideración de las limitaciones al crecimiento como parámetro de sostenibilidad del medio ambiente urbano
}

\author{
Juan Francisco Sánchez González
}

Secretario-Interventor de Administración Local

Servicio Provincial de Asesoramiento a Municipios

Diputación Provincial de Málaga

SUMARIO: I. INTRODUCGIÓN. II. LA LIMITACIÓN AL CRECIMIENTO COMO CRITERIO DE SOSTENIBILIDAD EN LA LEGISLACIÓN DE ORDENACIÓN TERRITORIAL Y URBANÍSTICA ANDALUZA. 1. Génesis de la introducción del criterio de crecimiento de la población como factor de sostenibilidad en el artículo 45 (N) del POTA. 2. El carácter reglamentario del POTA. 3. Las determinaciones del POTA y su distinto grado de aplicación. 4. La positivización en el POTA de las limitaciones a los crecimientos urbanísticos. 5. En el POTA no se dice lo que dicen que dice el POTA. 6. La modulación por el Decreto 11/2008 de los parámetros de crecimiento establecidos en el artículo 45 del POTA. III. LA LIMITAGIÓN AL CREGIMIENTO GOMO GRITERIO DE SOSTENIBILIDAD EN LA LEY DE SUELO ESTATAL. 1. La incorporación de criterios de sostenibilidad en la regulación estatal del régimen de suelo. 2. La adaptación de la legislación territorial y urbanística de las distintas Comunidades Autónomas a las exigencias derivadas del artículo 15.6 de la Ley de Suelo. 3. La necesidad o procedencia de la adaptación de la legislación territorial y urbanística en el caso de Andalucía. 4. La sostenibilidad como paradigma de la legislación territorial y urbanística en Andalucía y la innecesariedad de su adaptación a la Ley Estatal de Suelo en éste extremo. IV. CONCLUSIONES. 


\section{RESUMEN}

La límitación al crecimiento urbanístico, ante la gravedad de la utilización de un urbanismo basado en un crecimiento exponencial, atendidas las voces de alarma y los constantes y contundentes pronunciamientos de todas las instituciones, desde las más altas instancias de las Naciones Unidas hasta la Administración autonómica, pasando por la Administración Estatal y la Comunidad Económica Europea, constituyen más una obligación que una opción para el legislador ambiental y territorial. Sin embargo no parece que puedan abrirse paso sin dificultad polícitas aceptables y aceptadas, a los ritmos de crecimiento urbanístico si el ordenamiento normativo territorial y urbanístico no consigue reunir unas mínimas cualidades de congruencia, de transparencia y que tenga vocación de continuidad.

Palabras claves: Limite crecimiento; Sostenibilidad; Medio Ambiente Urbano; POTA; Ley de Suelo 2008.

\section{ABSTRACT}

The límitacion to the urban development growth, before the gravity of the utilization of an urbanism based on an exponential growth, attended the voices of alarm and the constant and forceful pronouncements of all the institutions, from the highest instances of the United Nations up to the autonomous Administration, happening for the State Administration and the Economic European Community, constitute more an obligation than an option for the environmental and territorial legislator. Nevertheless it does not seem that way could be made without difficulty polícitas acceptable and accepted, to the paces of urban development growth if the normative territorial and urban development classification does not manage to assemble a few minimal qualities of congruity, of transparency and that it has vocation of continuity.

Keywords: Limit growth; Sustainability; Urban Environment; POTA; Land Act 2008.

\section{INTRODUCCIÓN}

Como pusiera de relieve la Comisión Europea en su Comunicación «Hacía una estrategia temática sobre el Medio Ambiente Urbano», ${ }^{1}$ el tema del urbanismo está llamado a adquirir una importancia creciente a medida que se consolidan las tendencias de

\footnotetext{
${ }^{1}$ Comunicación de la Comisión al Consejo, al Parlamento Europeo, al Comité Económico y Social Europeo y al Comité de las Regiones de 11 de febrero de 2004 (COM [2004] 60 final, Bruselas, 11.02.2004). Epígrafe 2.4 (Urbanismo sostenible), apartado 2.4.1 (Porqué es una prioridad el urbanismo sostenible).
} 
cambio demográfico y medioambiental. El aumento de la esperanza de vida y el aumento de las poblaciones con carácter más o menos estable, fruto de los procesos migratorios o simplemente el aumento de los flujos de turismo residencial hacia zonas en las que el clima benigno representa un factor determinante, o simplemente los cambios en las tendencias de uso y ocupación de las viviendas mediante los cuales se hace más frecuente la existencia de viviendas ocupadas por un solo habitante, todos ellos son factores que ayudan a comprender la paradoja que representa que mientras la población total de Italia, Grecia, España y Portugal está disminuyendo, el número de viviendas haya aumentando espectacularmente en los últimos años.

En lo que se refiere al urbanismo, la expansión urbana es el aspecto más preocupante y necesitado de una respuesta adecuada. La Comisión da la voz de alerta al constatar que las ciudades se están expandiendo invadiendo zonas rurales a un ritmo más rápido que el crecimiento de la población ( $20 \%$ de expansión en los últimos 20 años, con sólo un 6\% de incremento de la población). En cuanto a los usos del suelo, se sustituyen los espacios verdes (regiones agrícolas o naturales de gran valor) por zonas destinadas a viviendas de baja densidad, en no pocas ocasiones desconectadas orgánica y funcionalmente de la ciudad de la que dependen, o con fines comerciales. Esta expansión urbana refuerza la necesidad de desplazamientos y la dependencia del automóvil, aumentando así la congestión del tráfico, el consumo de energía y las emisiones contaminantes, lo que a la postre se traduce en unos efectos colaterales de un urbanismo mal concebido que agudizan la insostenibilidad ${ }^{2}$ ambiental del mismo.

Los problemas propios de un sistema urbanístico basado en un continuo e incontrolado crecimiento y expansión de la ciudad con la consiguiente huella ecológica que ello genera, se agudizan cuando la densidad de población disminuye y cuando las actividades cotidianas (ir a casa, al trabajo, y de compras) implican largos trayectos, lo que favorece la aparición de nuevos problemas medio ambientales derivados de la movilidad, contaminación de todo tipo, etc.... Ante tan desalentador panorama considera necesario la Comisión que se ponga el acento en la planificación de «la expansión de las ciudades de forma que encaje en una estrategia a largo plazo en la que el impacto medioambiental sea mínimo y claramente precisado, e impidiendo que se produzca un proceso incontrolado de expansión urbana», y propone para ello "crear incentivos que fomenten el urbanismo sostenible, por ejemplo medidas para dificultar la construcción en terrenos vírgenes» a la vez que se-

\footnotetext{
${ }^{2}$ Por contraposición al término «insostenibilidad» el término «sostenibilidad» se utiliza como sinónimo de sustentabilidad y se refiere al equilibrio de una especie con los recursos de su entorno, por extensión se utiliza también cuando nos referimos a la explotación de un recurso por debajo de su límite de renovación. Desde el punto de vista del progreso de la humanidad, según el Informe Brundtland (1987), la sostenibilidad consiste en la capacidad de satisfacer las necesidades de la actual generación sin sacrificar la capacidad de futuras generaciones de satisfacer sus propias necesidades.
} 
ñala que las «estrategias y políticas para las zonas urbanas deben relacionarse con las estrategias regionales y nacionales con el fin de garantizar su concordancia y evitar que las iniciativas locales queden desvirtuadas».

Para poner freno a la incontrolable e insostenible expansión urbana fuera de toda lógica ambiental, en la Planificación Urbanística, como técnica de protección del Medio Ambiente, se introducen criterios que descansan en la consideración del crecimiento de la población como parámetro de la sostenibilidad del medio ambiente urbano. En unas ocasiones tales criterios obligan a recurrir a controles más reforzados sobre el ejercicio de las potestades de planeamiento (v. gr. estableciendo la necesidad de que ante previsibles incrementos más o menos importantes de población se deba recurrir a la revisión integra del planeamiento) en otras ocasiones dichos criterios consisten en límites o techos de crecimiento infranqueable para el planeamiento municipal.

\section{LA LIMITACIÓN AL GRECIMIENTO COMO CRITERIO DE SOSTENIBILIDAD EN LA LEGISLACIÓN DE ORDENA- CIÓN TERRITORIAL Y URBANÍSTICA ANDALUZA}

Aprobada por el Pleno del Parlamento los días 9 y 10 de diciembre de 1993 en el Boletín Oficial de la Junta de Andalucía de fecha 22 de enero de 1994 y en el Boletín Oficial del Estado de 9 de febrero de 1994 se publica la Ley de Ordenación Territorial de Andalucía (en adelante LOTA). Más de un año después, el Consejo de Gobierno de la Junta de Andalucía, mediante Decreto 83/1995, de 28 de marzo, acuerda la formulación del Plan de Ordenación del Territorio de Andalucía, conforme al mandato establecido en el artículo 8 de la Ley.

De conformidad con la Exposición de Motivos de la Ley, es objeto del Plan de Ordenación del Territorio de Andalucía (en adelante POTA) establecer la «organización y estructura territorial que se pretende para la Comunidad Autónoma, constituyendo el marco de referencia territorial para los Planes de Ordenación del Territorio que se efectúen para ámbitos menores y para los Planes con Incidencia en la Ordenación del Territorio. Asimismo, este instrumento debe servir de referente para la planificación del Estado y de la Unión Europea, en aquellas materias que tengan incidencia territorials.

Transcurridos más de once años, mediante Decreto 129/2006, de 27 de junio, el Consejo de Gobierno aprobó el POTA y lo remitió al Parlamento de Andalucía. Finalmente, el Parlamento en su sesión del 25 y 26 de octubre de 2006 dio el visto bueno al documento tras incluir varias modificaciones. 


\section{Génesis de la introducción del criterio de crecimiento de la po- blación como factor de sostenibilidad en el artículo 45 (N) del POTA.}

El origen del artículo 45 que con carácter de Norma (N) se incluye en el Título II del POTA está en las propuestas de resolución dirigidas a la mesa de la Comisión de Infraestructuras, Transportes y Vivienda del Parlamento de Andalucía presentadas por el Grupo Parlamentario de Izquierda Unida Los Verdes-Convocatoria por Andalucía.

La propuesta de Resolución número 13 formaba parte de una serie de propues$\operatorname{tas}^{3}$ que en relación al POTA presentó el Grupo Parlamentario señalado y aunque no incluía una motivación individualizada, la misma está implícita en el primer párrafo que encabezaba el grupo de Resoluciones en el que el Grupo proponente manifestaba que «El proyecto de Plan de Ordenación del Territorio de Andalucía (POTA) presentado por el Consejo de Gobierno NO ES UN VERDADERO PLAN DE ORDENACIÓN DEL TERRITORIO. Al margen de su desacertado modelo territorial, únicamente contiene una serie de buenas intenciones bajo la forma de directrices y recomendaciones, así como de normas de escaso nivel de compromiso, que se supone serán de aplicación en futuros planes territoriales $y$, sobre todo, sectoriales. Planes que, de seguir la tendencia mostrada hasta ahora y en la medida en que están fuertemente condicionados por sus planes predecesores de los que son herederos, serían contradictorios con el POTA y plantearían objetivos distintos a los de éste, especialmente en lo que respecta a un desarrollo equilibrado y cohesionado social y territorialmente y a la sostenibilidad ambientals por lo que de acuerdo con dicha motivación, con el numeral y título «13. CRECIMIENTOS URBANISTIICOS DESMESURADOS» proponía la aprobación de la siguiente RESOLUCIÓN: «El Parlamento de Andalucía insta al Consejo de Gobierno a que el POTA incluya como norma y con carácter general límites a los crecimientos urbanísticos desmesurados de los municipios andaluces. En base a ello, no se admitirán los crecimientos que supongan incrementos de suelo urbanizable superiores al 40\% del suelo urbano disponible ni los crecimientos que supongan incrementos de población superiores al $30 \%$ en ocho años». En la defensa de la propuesta de Resolución, el portavoz del Grupo proponente manifestaba ${ }^{4} \ll$ Se está planteando, por todos los que hablan de esto, como un elemento fundamental para terminar con la especulación y la corrupción urbanistica el poner límite a los crecimientos. Pero no basta con formularlo. Por eso Izquierda Unida plantea una propuesta concreta, que limita el crecimiento del suelo urbanizable al $40 \%$ del suelo urbano existente, y de la población previsible, crecimiento de la población previsible, en ocho años al

\footnotetext{
${ }^{3}$ Boletín Oficial del Parlamento de Andalucía Número 533 de fecha 23 de octubre de 2006 páginas 29260-29261.

${ }^{4}$ Diario de Sesiones del Parlamento de Andalucía (98/VII Legislatura) de fecha 25 de octubre de 2006 página 6610 .
}

Revista Andaluza de Administración Pública

ISSN: 0034-7639, núm. 81, Sevilla, septiembre-diciembre (2011), págs. 13-46 
30\% del actual. De esta manera, sólo de esta manera, limitando cuantitativamente los crecimientos, podremos alcanzar un crecimiento sostenible».

Tras el correspondiente debate y aprobación de las Resoluciones que el Parlamento consideró conveniente incorporar, el 29 de diciembre de 2006 fue publicado el POTA en el Boletín Oficial de la Junta de Andalucía.

\section{El carácter reglamentario del POTA.}

Debe señalarse que el POTA goza de la misma naturaleza de norma reglamentaria que la que de forma unánime y pacífica se atribuye a los Planes Generales de ordenación urbanística ${ }^{5}$. La integración del POTA en el ordenamiento jurídico, supone, en atención al principio de jerarquía normativa constitucionalmente garantizado, que sus determinaciones deben respetar y cumplimentar la norma superior que directamente lo regula y de la que directamente trae causa, la LOTA, sumisión jerárquica que también es predicable de todas aquellas otras normas que puedan afectarle «por ubicarse en un escalón jerárquico superior e incidir sobre unos u otros aspectos de su contenido, que, consiguientemente, deben asumir un determinado sentido» para el TSJA resulta claro que la LOTA «ha querido reservar al Plan territorial un papel exclusivamente reglamentario, tal vez más adecuado a la línea jerárquica que debe guardar con la propia Ley de Ordenación del Territorio, como norma superior que cierra el sistema normativo y que debe regir las determinaciones de aquébs, conclusión a la que llega tras constatar que el propio Legislador, de forma contraria a lo establecido en otros supuestos distintos, en los que la intervención de la Asamblea Legislativa en la elaboración de instrumentos del ordenación general del territorio se prevé en forma de Ley, ha descartado su intervención a través del instrumento normativo mediante el cual ejerce su función legislativa, por lo que a ojos

\footnotetext{
${ }^{5}$ Así lo ha venido a confirmar el TSJA (Sede de Málaga) que en Sentencia 5119/2010 de 23 de diciembre de $2010\left(\mathrm{FJ}^{\circ}\right.$ ) afirma "Resulta esencial reconocer la naturaleza normativa del Plan, en cuanto que se integra en el ordenamiento jurídico y lo innova, sin que su aplicación determine el agotamiento de su eficacia, lo que, como es bien sabido, excluye de su concepto a los actos administrativos generales, como elementos ordenados por aquél, que se limitan a aplicar la norma en un supuesto dado. Asi se han considerado tradicionalmente los instrumentos de planificación urbanística, cuya naturaleza normativa no se cuestiona respecto de los de alcance general, es decir, los Planes Generales de Ordenación o las Normas Complementarias o Subsidiarias de Planeamiento (...). En cuanto a la planificación territorial, aunque la jurisprudencia no ha sido demasiado explícita al resaltar su naturaleza normativa (...), ésta se extrae sin esfuerzo de su superioridad jerárquica que legalmente se proclama desde hace tiempo respecto de los planes directores territoriales de coordinación, introducidos por la Ley 19/1975, de 2 de mayo, de reforma de la Ley del Suelo de 1956, y a cuyas determinaciones debian someterse los Planes Generales de Ordenación Urbana (artículos 10.2 del Texto Refundido de la Ley del Suelo, aprobado por Real Decreto Legislativo 1346/1976, de 9 de abril, y 69.2 y 70.2 del Texto Refundido de la Ley del Suelo aprobado por Real Decreto Legislativo 1/1992, de 26 de junio). Por lo mismo, la vinculatoriedad de los actuales planes de ordenación del territorio sobre los planes urbanísticos sólo puede significar que aquellos participan también de la naturaleza normativa de estos».
} 
de la Sala resulta evidente que «la intervención que en este ámbito se ha reservado el Parlamento andaluz no tiene naturaleza legislativa sino que debe integrarse entre las de control de la actividad del Gobierno en relación con el examen de los programas y planes» remitidos a aquél por este (STSJ Andalucía 5119/2010 FJ 4º.

Desde esta perspectiva, «la naturaleza reglamentaria del Plan de Ordenación del Territorio determina ante todo su sometimiento a la Ley, que, consecuentemente, no podrá ser soslayada so pretexto de la intervención del Parlamento de Andalucías. El POTA, por tanto, debe someterse a lo establecido en las Leyes y en concreto a lo establecido en la LOTA a la que debe subordinación jerárquica.

Así lo ha declaradlo el Alto Tribunal andaluz en Sentencia 5119/2010 de 23 de diciembre de $2010\left(\mathrm{FJ}^{\circ}{ }^{\circ}\right.$ ) confirmándolo el mismo Tribunal en Sentencia 5120/2010 de la misma fecha ( $\mathrm{FJ} 2^{\circ}$ ), lo que justifica las airadas críticas que tempranamente se realizaron a la pretendida aplicación directa de las determinaciones del POTA, fundamentalmente las que se refieren a las limitaciones de los crecimientos urbanísticos «ex» artículo 45, pues como más adelante se expone, la LOTA sólo establece la vinculatoriedad directa del POTA para los Planes Subregionales y Planes con Incidencia en la Ordenación del Territorio, aunque estos sean anteriores en el tiempo, supuesto que, de producirse, provoca la obligación de adaptación (artículo 22.1 y 22.2 LOTA); vinculación directa que no se produce respecto de los Planes de Ordenación Urbanística (ni tampoco para los Planes con incidencia en la Ordenación del Territorio) efecto que se reserva para los Planes de Ordenación del Territorio de ámbito subregional (LOTA artículo 23.1).

\section{Las determinaciones del POTA y su distinto grado de aplica- ción.}

Las determinaciones del POTA despliegan sus efectos con distinto grado de intensidad dependiendo de que sus previsiones se califiquen como normas, directrices y recomendaciones (artículo 21 LOTA) tipología de determinaciones que son las originariamente establecidas en la LOTA pero a las que el propio POTA (artículo 2) añade otras dos: los objetivos y las líneas estratégicas.

Las normas «son determinaciones de aplicación directa vinculantes para las Administraciones Públicas y para los particulares, en los suelos urbanizables y no urbanizables». Como distintos autores han recordado el significado que nuestros Tribunales Superiores han atribuido a éstas «normas» es el de «albergar pautas, paradigmas o reglas de inmediata obligación, siendo disposiciones sustantivas de ordenación que tienen vocación de aplicabilidad y vinculatoriedad absoluta, rotunda e inmediata, pues estiman que son un trasunto de las «normas de aplicación directas urbanisticas, $y$, por ende, con independencia de la existencia o no de otro Plan (ya sea territorial 
o urbanistico» ${ }^{6}$ de manera que sus determinaciones concretas prevalecen a las de otros planes que se encuentren jerárquicamente subordinados al POTA por simple aplicación del principio de jerarquía normativa y todo ello sin necesidad de adecuación de éstos otros planes para su plena eficacia y aplicación, aseveración que encuentra apoyo no sólo en la literalidad de lo dispuesto en el artículo 21 y 23 LOTA sino que recuerda también el artículo 35 apartado 3 de la LOUA al disponer que: "La entrada en vigor sobrevenida de Planes de Ordenación del Territorio de ámbito subregional comportará: a) La prevalencia de sus normas de aplicación directa cuando éstas sean contrarias o incompatibles con las determinaciones del instrumento de planeamiento urbanístico b) La adaptación de las normas del instrumento de planeamiento urbanístico en la forma que establezcan sus directrices. c) La obligación del municipio o municipios afectados de proceder a la innovación de sus instrumentos de planeamiento urbanístico para la adaptación de sus determinaciones a las de la planificación territorial en los términos previstos en éstas».

Consecuentemente nos encontramos en presencia de preceptos de inmediata eficacia y vinculación, por lo que son de inexcusable observancia con independencia de que existan o no planes, de un texto normativo que se impone al resto de planificadores, teniendo por no puestos (o decaídos) aquellos preceptos contenidos en otras figuras de planeamiento que entren en contradicción con sus postulados. Por ello se sostiene que las «normas» ostentan un carácter imperativo, aunque su aplicación se limite al suelo urbanizable y no urbanizable al que se aplican de forma inmediata y sin necesidad de adaptación o innovación del resto de planes inferiores jerárquicamente al POTA.

No obstante, como precisa la Sentencia del TSJA (Málaga) 5119/2010 de 23 de diciembre de 2010, se trata de una "previsión cuy a evidente finalidad es la de limitar la intervención sustantiva del planeamiento territorial en el suelo urbano, reservando allí naturalmente una mayor intensidad a la ordenación urbanística, aunque lo cierto es que también para este suelo el Plan de Ordenación del Territorio puede establecer normas de alcance adjetivo o formal, como, por ejemplo, las que definen la propia naturaleza del Plan (apartado 1) o la gestión de la política territorial (apartado 7), que se refieren a todo el territorio andaluz, incluido el suelo urbano, pero que, en realidad, no sirven para ordenarlo ni, por lo tanto, desconocen la finalidad de aquella previsión legislativas $\left(\mathrm{FJ} 4^{\circ}\right)$.

Por su parte, las directrices «son determinaciones vinculantes en cuanto a sus fines. Con sujeción a ellas, los órganos competentes de las Administraciones Públicas a quienes corresponda su aplicación establecerán las medidas concretas para la consecución de dichos fines». Las recomen-

\footnotetext{
${ }^{6}$ CABRAL GONZÁLEZ-SICILIA, Ángel (2011): «Hacia una más correcta interpretación y una más adecuada aplicación del Plan de Ordenación del territorio de Andalucía». Práctica Urbanística. Número 104. Sección Estudios. Mayo 2011. Editorial LA LEY, página 29.
} 
daciones «son determinaciones de carácter indicativo dirigidas a las Administraciones Públicas que, en caso de apartarse de las mismas, deberán justificar de forma expresa la decisión adoptada y su compatibilidad con los objetivos de la Ordenación del Territorion. Los objetivos son los que «enuncian la finalidad última a alcanzar con el desarrollo y aplicación del Plan». Finalmente, las Líneas Estratégicas son aquellas que «definen la orientación general de la actuación pública para materializar los fundamentos básicos del Modelo Territorial de Andalucía, sobre la base de los principios de planificación, coordinación, cooperación y participacións

\section{La positivización en el POTA de las limitaciones a los creci- mientos urbanísticos.}

La polémica suscitada fundamentalmente por la introducción de las limitaciones al crecimiento de las poblaciones y de la urbanización de territorios a través del artículo 45 del POTA ha ensombrecido y desplazado a un segundo plano la constatación de que por primera vez en una norma de ordenación territorial se hayan introducido en nuestra comunidad criterios que hacen posible una ordenación territorial y urbanística más sostenible y amable con el medio ambiente.

Esquemáticamente puede destacarse la regulación que con carácter de Norma se incorpora al POTA y que se refiere a la defensa de un sistema y un modelo de ciudad adecuada en su conjunto a la tradición mediterránea, una ciudad compacta y sostenible (artículo 45); lo dispuesto en relación con el desarrollo de estrategias de política de suelo con destino a viviendas protegidas así como en relación con la formación de los patrimonios públicos de suelo (artículo 50.3.b); la apuesta que el Plan realiza por modelos urbanos que favorezcan la ciudad multifuncional, equilibrada y accesible con un adecuado tratamiento de los problemas de movilidad en los centros urbanos y en la ordenación del crecimiento de la ciudad, incorporando criterios de diversidad, proximidad y complejidad en la trama urbana regulación que se contiene en sus artículos 46.1.b, 54 y 59.6, con carácter de Directrices (D); o, en definitiva, en la regulación que también con carácter de Norma $(\mathrm{N})$ y con la finalidad de garantizar la sostenibilidad del planeamiento y la garantía de los recursos hídricos para las futuras actuaciones de transformación urbanística, establece el artículo 96 POTA.

Sin embargo, como se apuntaba anteriormente, pese a la indudable trascendencia para conseguir un medio ambiente más sostenible que tienen determinaciones como las trascritas, todo el foco de atención se ha centrado, básicamente, en tres aspectos: 1) La pretensión de aplicación directa de unas determinaciones (las del POTA) que según la Ley a la que jerárquicamente está subordinado no vinculan directamente al planeamiento; 2) Las pretensiones de aplicación de las determinaciones del POTA con carácter retroactivo a todo el planteamiento en tramitación en los momentos en que 
se publica el $\mathrm{Plan}^{7}$, y 3) el propio contenido del artículo 45.4.a del POTA y las limitaciones de los crecimientos urbanísticos que contiene. ${ }^{8}$ La incorporación de esta previsión al artículo 45 del POTA ha provocado aceradas críticas de la doctrina administrativa, así por ejemplo RECUENCO AGUADO ${ }^{9}$ manifestaba su sorpresa señalando «se trata de una norma indiscriminada para todos los Municipios de Andalucía, sin referencia alguna a su infinita diversidad, ni a la realidad económica, o social o geográfica: ¡Nada! • Todos los municipios de Andalucía quedan fijados en su actual situación poblacional y dimensional y, consecuentemente, en su jerarquía, y todos quedan obligados a crecer lo mismo. - Sin diferenciar la escala: Sea un municipio de 1000 habitantes o de un millón. - Sin diferenciar la localización: En la Sierra de Cazorla o en la Costa del Sol. • Sin diferenciar su dimensión: Municipios que han colmatado todo su T.M. y Municipios con Términos inmensos» y denunciaba que de facto se había convertido al POTA «que es un mero Planeamiento Territorial, en una Ley, que de paso deroga parcialmente la LOUA, porque ésta deja claro que el Suelo Urbanizable se dimensionará según el crecimiento previsible, y de ninguna forma limitado al 40\% de la superficie del suelo urbano (artículo 10.1.A.a, y artículo 47.b)». JORDANO FRAGA señala sin embargo que «por la razón que se invoca, el POTA no es ilegal pues [entiende que] el artículo 7 de la Ley 1/1994, de 11 de enero, de Ordenación del Territorio de Andalucía, habilita para la fijación de dichos límites». ${ }^{10}$

${ }^{7}$ Debe recordarse que la Disposición Transitoria Segunda apartado 2 ( $2^{\circ}$ párrafo) de la Ley 7/2002 de Ordenación Urbanística de Andalucía (LOUA), dispone que "Transcurridos cuatro años desde la entrada en vigor de esta Ley, no podrán aprobarse modificaciones del planeamiento general que afecten a las determinaciones propias de la ordenación estructural, a dotaciones o a equipamientos cuando dicho instrumento de planeamiento no haya sido adaptado a la presente Ley, al menos, de forma parcials. Dado que la publicación de la LOUA se produjo en el BOE número 12, de 14 de enero de 2003 el plazo de 4 años concluía el día 14 de enero de 2007 por lo que en las fechas de publicación del POTA (29 de diciembre de 2006) eran numerosos los Ayuntamientos de nuestra Comunidad que habían iniciado la tramitación de la Revisión de sus instrumentos de Planeamiento, habiendo muchos superando la fase de aprobación del Avance, otros la Aprobación Inicial de sus respectivos Planes de Ordenación Urbanística e incluso alguno la fase de Aprobación Provisional de los mismos; a todos ellos, se encontrasen en la fase de tramitación que se encontrasen, se pretendió aplicar las restricciones al crecimiento establecidas en la Norma 45.4.a POTA. Frente a ello la doctrina (CABRAL GONZÁLEZ-SICILIA, Ángel (2011), página 31) señala que «el hito primordial sobre el que ha de gravitar la efectiva aplicación de las normas del POTA (y sobre todo de los nuevos paradigmas taxativos contenidos en su artículo 45) queda prefijado en el instituto de la «formulación» de los instrumentos de planeamiento, no rigiendo, por ende, esas pautas a los procesos de innovación de Planes que se encuentren en un período de tramitación más avanzado».

${ }^{8}$ Dice así el artículo 45.4.a: « (...) 4. Como norma y con criterio general, serán criterios básicos para el análisis y evaluación de la incidencia y coherencia de los Planes Generales de Ordenación Urbanística con el modelo de ciudad establecido en este Plan los siguientes: a) La dimensión del crecimiento propuesto, en función de parámetros objetivos (demográfico, del parque de viviendas, de los usos productivos y de la ocupación de nuevos suelos por la urbanización), y su relación con la tendencia seguida para dichos parámetros en los últimos diez años, debiendo justificarse adecuadamente una alteración sustancial de los mis$\underline{\text { mos. }}$ Con carácter general no se admitirán los crecimientos que supongan incrementos de suelo urbanizable superiores al $40 \%$ del suelo urbano existente ni los crecimientos que supongan incrementos de población superiores al 30\% en ocho años».

${ }^{9}$ RECUENCO AGUADO, Luís (2006): «La coordinación de la planificación territorial». Revista Andaluza de Administración Pública. Número 63. 2006, páginas 255-256.

${ }^{10}$ JORDANO FRAGA, Jesús (2009): «Políticas Autonómicas de Medio Ambiente. XIV. Andalucía: Desarrollo sostenible y límites a los crecimientos urbanísticos». Obra colectiva «Observatorio de Políti- 
A pesar de todo ello, la realidad como sostiene GUTIÉRREZ COLOMINA ${ }^{11}$ es que más allá de las posibles ilegalidades del POTA, si a la entrada en vigor de la Ley estatal de Suelo (que ha supuesto el fin a la liberalización indiscriminada del suelo, otorgándole a todo el suelo rural un valor digno de ser protegido) «le sumamos las interpretaciones restrictivas para coordinar el desarrollo urbanístico con el modelo territorial incorporado en el POTA, que ha realizado la Junta de Andalucía, junto a la crisis inmobiliaria, la consecuencia es un frenazo a los nuevos crecimientos urbanísticos en la Comunidad Autónoma de Andalucías.

\section{En el POTA no se dice lo que dicen que dice el POTA.}

Con el título que encabeza éste apartado quiere ponerse de relieve que del texto del artículo 45.4.a del POTA no pueden extraerse las conclusiones que muchos obtienen de una precipitada lectura propiciada por una práctica más o menos cicatera de los órganos administrativos llamados a aplicar la Norma.

Precisa JORDANO FRAGA ${ }^{12}$ que en los momentos que realizaba la afirmación (2009), la interpretación que realizaba la Junta de Andalucía de la Norma 45 del POTA, admitía que los municipios pudieran plantear en sus respectivos planes urbanísticos nuevos suelos urbanizables que superasen los límites establecidos en el POTA, pero «con la condición de que los excesos no pudieran desarrollarse hasta pasados ocho años de vigencia de los mismos. Esta fórmula ha permitido aprobar planes de ordenación urbana de municipios que habian previsto inicialmente crecimientos superiores a los límites: por ejemplo los de Pruna, La Rinconada y Villanueva del Ariscal (Sevilla), Familena, Torreperogily Villacarrillo (faén) y Alfacar (Granada)».

En no pocas ocasiones se ha achacado a la Administración andaluza que se estaba legislando sobre la base de instrucciones modulando, cuando no realmente forzando, la interpretación de la literalidad de la norma, y éste es uno de los casos. La afirmación realizada por JORDANO FRAGA no es más que la constatación de lo que transcribe la Instrucción 1/2007 de 10 de mayo de 2007 de la Secretaría General de Ordenación del Territorio, relativa a la elaboración y tramitación de los informes de incidencia territorial ${ }^{13}$ de los Planes Generales de Ordenación Urbanísti-

cas Ambientales 2009» coordinada por López Ramón, Fernando. Thomson Reuters Aranzadi. 2009, página 324 .

${ }^{11}$ GUTIÉRREZ COLOMINA, Venancio (2008): «POTA I. La Autonomía Local versus discrecionalidad Autonómica en la Ordenación Territorial y Urbanística de Andalucía». Cuadernos de Gestión Pública Local. Instituto Superior de Economía Local (ISEL). Diputación Provincial de Málaga. 2008, página 125.

${ }^{12}$ JORDANO FRAGA, Jesús (2009): 323.

${ }^{13} \mathrm{El}$ carácter preceptivo del Informe de Incidencia Territorial fue introducido en la Ley 7/2002 por 
ca. En dicha Instrucción la Administración Autonómica ordenaba que la valoración contenida en el informe de Incidencia Territorial se centrase en tres aspectos básicos: «a) La coherencia del desarrollo urbanístico propuesto con el modelo establecido en el Plan de Ordenación del Territorio de Andalucía y en el Plan de Ordenación del Territorio de ámbito subregional en su caso; b) La justificación del crecimiento propuesto en función de parámetros objetivos referidos a la evolución en los Últimos 10 años o a las nuevas circunstancias que pudiesen concurrir y c) La incidencia de la ordenación propuesta sobre el sistema de asentamientos y la formación de nuevos núcleos de población, su justificación y alcances. La aplicación de ésta Instrucción y en concreto en el caso del municipio sevillano de «La Rinconada» motivó incluso la intervención de Oficio del Defensor del Pueblo Andaluz.

En efecto, requerido informe por parte del Defensor del Pueblo ${ }^{14}$ a la Secretaría General de Ordenación del Territorio y una vez emitido el mismo, el Comisionado del Parlamento Andaluz plantea sus dudas respecto al alcance de la Instrucción en cuanto se refiere a la exclusión de los Suelos Urbanizables No Sectorizados al entender que «en modo alguno, está previsto en el artículo 45.4 a del POTA, ya que se habla exclusivamente de suelo urbanizable, sin distinguir entre sectorizado y no sectorizado. Nos encontrariamos, por tanto, ante un documento administrativo que vendría a establecer distintos tratamientos del suelo urbanizable, cuando precisamente el propio POTA, de evidente superior rango normativo, no lo hace» por lo que concluye que «la interpretación que se realizaba por parte de la Instrucción suponía una clara vulneración del principio constitucional de jerarquía normativa y generaba (...) una cierta inseguridad jurídica, pues los municipios que, en gran medida, son los destinatarios del POTA podrían considerar que, si es posible tal interpretación que no se desprende de la lectura del POTA, también pueden tener cabida otro tipo de interpretaciones que, en principio, no resultarían justificadas en base a la lectura de las determinaciones del citado POTA\%. Concluye su informe el Alto Comisionado del Parlamento Andaluz señalando que de la sugerencia de difusión

\footnotetext{
el artículo 29 de la Ley 13/2005 de 11 de noviembre de medidas para la Vivienda Protegida y el Suelo, incorporando a la LOUA la Disposición Adicional 8 a cuyo tenor literal es el siguiente: «Contenido del informe de incidencia territorial sobre los Planes Generales de Ordenación Urbanística En la tramitación de los Planes Generales de Ordenación Urbanistica, el informe que ha de emitir el órgano competente en materia de ordenación del territorio, conforme a lo dispuesto en el artículo 32, apartado 1, regla $2^{a}$ de esta Ley, analizará las previsiones que las citadas figuras de planeamiento deben contener según lo dispuesto en la disposición adicional segunda de la Ley 1/1994, de Ordenación del Territorio de Andalucía, de 11 de enero, así como su repercusión en el sistema de asentamientos». Por otro lado, la Disposición Adicional $2^{a}$ de la Ley 1/1994 de 11 de enero de Ordenación del Territorio de Andalucía dispone que: "El Planeamiento Urbanístico General y el Planeamiento Especial a que hace referencia el artículo 84.3 del Texto Refundido de la Ley sobre Régimen de Suelo y Ordenación Urbana contendrán, junto a las determinaciones previstas por la legislación urbanística, la valoración de la incidencia de sus determinaciones en la Ordenación del Territorio, particularmente en el sistema de ciudades, sistema de comunicaciones y transportes, equipamientos, infraestructuras o servicios supramunicipales y recursos naturales básicos».

14 «Informe del Defensor del Pueblo Andaluz al Parlamento de Andalucía sobre la Gestión realizada durante 2008». Boletín Oficial del Parlamento de Andalucía Número 231 de fecha 7 de mayo de 2009 páginas $68-71$.
} 
del conocimiento de la Instrucción que dicho órgano realizó y de la respuesta recibida por el órgano autonómico «entendimos que la Secretaría General no compartía su contenido por tratarse de un documento sin rango normativo y de orden interno, afectante únicamente a los propios órganos de la Consejería de Obras Públicas y Transportes. Como es lógico, respetábamos su divergencia, pero seguíamos creyendo que hubiera resultado deseable su difusión para orientar a los municipios que redactaban su planeamiento general, sobre los criterios interpretativos de la Administración Autonómica sobre estos conceptos jurídicos indeterminados recogidos en el artículo 45 del POTA, eliminando con carácter previo posibles contradicciones del planeamiento urbanístico municipal con respecto al planeamiento territorial de la competencia de esa Consejería (...)».

La aplicación de las limitaciones a los crecimientos urbanísticos con base a los incumplimientos derivados de la ordenación territorial, se intentó aplicar incluso antes de que se introdujesen las limitaciones a los crecimientos derivadas de la Norma 45 del POTA (Plan que como recordamos se aprobó el 29 de diciembre de 2006). ${ }^{15}$

Parece incuestionable que, en contra del criterio y de la práctica que han mantenido los órganos autonómicos (al menos en cuanto a la operativa que se sigue en los Informes de Incidencia Territorial para determinar si los instrumentos urbanísticos municipales que examinan se ajustan a las determinaciones del POTA), el artículo 45.4.a no contiene reglas que puedan ser aplicadas como consecuencia de un simple cálculo automático. Se insiste, de la lectura del texto del artículo 45.4.a del POTA no

15 Corrobora esta afirmación la Sentencia del TSJA (Sevilla, Sala de lo Contencioso-Administrativo, Sección $2^{a}$ ) de 19 Diciembre de 2008. Recurso 1025/2006 (LA LEY/255357/2008). Se impugnaba en esa ocasión la resolución de la Comisión Provincial de Ordenación del Territorio y Urbanismo (CPOTU) de Sevilla de 12 de Mayo de 2006, por la que se aprobó definitivamente de forma parcial el proyecto del Plan General de Ordenación Urbana (PGOU) de Burguillos, suspendiendo la aprobación definitiva de las determinaciones que afectaban a determinados sectores de suelo urbanizable sectorizado suspensión que se fundamentaba en la alegación por el órgano autonómico entre otras cuestiones ligadas con el diseño de ciudad, en que el Plan establece un techo poblacional del municipio de 24.550 habitantes lo que corresponde a una capacidad de 7.672 viviendas, y que supone multiplicar por 5,43 la población que constaba en el censo de 2006 de 4.515 habitantes, crecimiento que está generado por la previsión de 3.482 nuevas viviendas en suelo urbanizable, y 634 en suelo urbano. Impugnaba ésta decisión el Ayuntamiento afectado argumentando la vulneración de la doctrina constitucional en materia de Autonomía Local y en materia de ordenación del territorio invadiendo con ello las competencias municipales. El Tribunal declara que: «Aunque discrepan las partes en cuanto al techo poblacional del municipio y al porcentaje de crecimiento de población (...) lo cierto es que tanto la capacidad de población o techo poblacional, como el modelo de ciudad son determinaciones de planeamiento que no tienen conexión con aspecto alguno de un modelo territorial superior ni inciden en aspectos de interés supramunicipal, por lo que no cabe el control de oportunidad de la Administración autonómica. En la resolución impugnada se invoca el artículo 3.1. a) de la LOUA, pero a la Administración demandada incumbía acreditar que con la aprobación provisional del PGOU por el Ayuntamiento no se conseguía el desarrollo sostenible y cohesionado [del municipio] o se empeoraban o no mantenían las condiciones de calidad de vida de la población (...) procede, por lo razonado, la estimación del recurso, anulando la resolución impugnada en lo que se refiere a la suspensión de la aprobación definitiva de las determinaciones correspondientes a los sectores [respecto de los que se acordó la suspensión de aprobación]» (FJ $\left.4^{\circ}\right)$.

Revista Andaluza de Administración Pública

ISSN: 0034-7639, núm. 81, Sevilla, septiembre-diciembre (2011), págs. 13-46 
se deduce que la aplicación de las limitaciones al crecimiento pueda ser fruto de un automatismo que, ni incorpora la norma, ni sería constitucionalmente aceptable desde el punto de vista del respeto a la autonomía municipal.

La afirmación de la ausencia de un automatismo del texto de la norma se deduce de las menciones contenidas en el propio artículo 45.4.a cuando señala que serán criterios básicos para el análisis de la incidencia territorial «La dimensión del crecimiento propuesto, en función de parámetros objetivos (demográfico, del parque de viviendas, de los usos productivos y de la ocupación de nuevos suelos por la urbanización, y su relación con la tendencia seguida para dichos parámetros en los últimos diez años)», cuando señala que dichos parámetros deberán ser analizados por su «... relación con la tendencia seguida para dichos parámetros en los últimos diez años», cuando se admite una alteración sustancial de las previsiones de crecimiento en relación con las registradas en los años precedentes aunque supeditado a que deba «justificarse adecuadamente una alteración sustancial de los mismos» y finalmente cuando establece que «Con carácter general no se admitirán los crecimientos que supongan incrementos de suelo urbanizable superiores al $40 \%$ del suelo urbano existente ni los crecimientos que supongan incrementos de población superiores al $30 \%$ en ocho años» pues si la limitación se establece con carácter general es porque, y siempre que quede justificado, pueden con carácter específico superarse la misma.

A mayor abundamiento existen distintas formas de calcular los crecimientos, el POTA sólo se refiere a crecimientos superiores al 30\% en 8 años sin precisar la forma en que ha de calcularse ese $30 \%$, así a falta de previsión expresa en contrario podría sostenerse que dado que el límite en 8 años es del $30 \%$ su correlativo crecimiento anual debería ser del 3,75\% (cociente de la división de 30 entre 8 ) si éste crecimiento es acumulativo (a la suma de la población del año base incrementada en el 3,75\% se le suma otro $3,75 \%$ y así sucesivamente hasta alcanzar el octavo año) el final del proceso nos arrojaría un crecimiento real de más del 34\% (comparando la población del año octavo año respecto de la del primero) y sin embargo no deja de ser también un $30 \%$.

Si tal como establece el POTA en su artículo 45.4.a como norma y con criterio general, son criterios básicos para el análisis y evaluación de la incidencia y coherencia de los Planes Generales de Ordenación Urbanística con el modelo de ciudad establecido en el POTA la «...dimensión del crecimiento propuesto, en función de parámetros objetivos (demográfico, del parque de viviendas, de los usos productivos y de la ocupación de nuevos suelos por la urbanización), y su relación con la tendencia seguida para dichos parámetros en los últimos diez años, debiendo justificarse adecuadamente una alteración sustancial de los mismos.» resulta obligado que el Informe de Incidencia Territorial deba considerar las tendencias de crecimiento seguidas en los municipios en los últimos años 10 años, obligación que no sólo es producto de la letra y espíritu de la Norma, sino de la más elemental con- 
sideración a la motivación que ha de presidir toda la actuación administrativa «ex» artículo 54 de la Ley de Procedimiento Administrativo.

Desde otros ámbitos el reproche a la Norma 45.4.a ha enfatizado que la falta de fundamentación en la regulación de las posibles excepciones a los límites de crecimiento establecidos «deja un margen absoluto a la discrecionalidad resultando incompatible con los principios de seguridad jurídica e igualdad y atentatoria para la autonomía locabs.

Comenzando por esto último, la cuestión ha podido ser resuelta por el Tribunal Superior de Justicia de Andalucía en Sentencias de fecha 23 de Diciembre de 2010 que recordando la doctrina del Tribunal Constitucional y del Tribunal Supremo en relación a la Autonomía Local y al Urbanismo ha tenido ocasión de señalar: «Por tanto, y como sintesis de la doctrina jurisprudencial sobre autonomía local, se puede afirmar: a) La garantía constitucional de la autonomía local es de carácter general y configuradora de un modelo de Estado. b) La efectividad de la autonomía local requiere que las leyes aseguren al municipio su derecho a intervenir en cuantos asuntos afecten directamente al círculo de sus intereses, con atribución de las competencias que proceda y de conformidad con los principios de descentralización y de máxima proximidad de la gestión administrativa a los ciudadanos -en ese sentido, por todas, sentencias del Tribunal Constitucional números 11/99, 54/04 y 240/06-; c) La autonomía local es un concepto jurídico de contenido legal, esto es, que permite configuraciones diversas, válidas en cuanto respeten el núcleo esencial de la garantía institucional de esa autonomía -por todas, sentencias del Tribunal Constitucional números 214/84 y 46/92-; d) La autonomía que se garantiza a los municipios en el artículo 140 de la Constitución es, pues, una autonomía en el marco de la Ley, sea estatal o sea autonómica, bien que el legislador debe respetar la esfera irreductible de la autonomía local. e) Por consiguiente, no es posible considerar vulnerado el reconocimiento y garantía de la autonomía municipal cuando se atribuye esa vulneración a actuación de otra Administración Pública que se ha llevado a cabo dentro de los límites previstos en la norma -en ese sentido, por todas, sentencias del Tribunal Supremo de 20 de octubre de 2004 y 9 de junio de 2008-. Pues bien, la ordenación del territorio, competencia propia de la Comunidad Autónoma, de acuerdo con el artículo 148.3 de la Constitución, y que ha tenido desarrollo legislativo autonómico por Ley 1/1994 y Ley 7/2002, permite que, al amparo de esta competencia, la intervención de la Administración Autonómica en esferas de competencia compartida con la Administración Local, si se hace dentro del marco de la norma, como se ha visto en fundamentos jurídicos precedentes, no pueda considerarse, a priori, como contraria a la autonomía locab. ${ }^{16}$

En cuanto a la autonomía local en materia urbanística, el TSJ de Andalucía (Sala de Málaga, Sentencia 5119/2010 de 23 de diciembre FJ $5^{\circ}$.b) recuerda la doctrina (la STS de 25 de octubre de 2006 y las que cita) en cuanto que ha venido a esta-

${ }^{16}$ En estos términos se pronuncia la Sentencia $5119 / 2010, \mathrm{FJ} 5^{\circ}$.c, de forma idéntica el FJ $3^{\circ}$.c de la Sentencia 5120/2010, y en términos muy similares FJ 5\%).

Revista Andaluza de Administración Pública

ISSN: 0034-7639, núm. 81, Sevilla, septiembre-diciembre (2011), págs. 13-46 
blecer que «la competencia autonómica de aprobación definitiva de los instrumentos de planeamiento municipal tiene un contenido preciso, derivado de la consolidación de la jurisprudencia de esta Sala desde la conocida Sentencia de Sala de 13 de julio de 1990, que distingue según se trate de los aspectos reglados o discrecionales del plan» y continúa exponiendo que en relación con los aspectos reglados «la Comunidad Autónoma tiene un control pleno, con alguna matización respecto de los conceptos jurídicos indeterminados, como señala la STS de 25 de octubre de 2006 (...) respecto a los aspectos discrecionales del plan, debemos distinguir, entre las determinaciones que afectan a un interés puramente local o municipal, o superior a este. Así, cuando el interés público concernido es municipal y no alcanza intereses que rebasen dicho ámbito, la competencia es estrictamente municipal, pues ha de prevalecer el modelo de ciudad que dibuja el Ayuntamiento, con la salvedad relativa al control tendente a evitar la lesión al principio de interdicción de la arbitrariedad de los poderes públicos «ex» artículo 9.3 Constitución Española» finalizando la Sala su fundamentación argumentando que "Las determinaciones discrecionales del plan, por otro lado, cuando afecten a materias que incidan sobre intereses supralocales, vinculándose con un modelo territorial superior al municipal, si permiten intervenir a la Administración autonómica corrigiendo, modificando o sustituyendo las determinaciones discrecionales del plan, establecidas en la fase municipal del procedimiento. Dicho de otra forma, el posible control o modificación por la Comunidad Autónoma de todos aquellos aspectos discrecionales del planeamiento, estará en función de los intereses públicos concernidos, y aún en el caso de tratase de intereses locales, únicamente, que no se haya lesionado la interdicción de la arbitrariedad de los poderes públicos».

Y en relación con la tacha de discrecionalidad en la apreciación por parte de la administración autonómica en los límites al crecimiento urbanístico y el atentado que ello podría suponer al principio de autonomía local que en el «diseño de la ciudad» ha de reconocerse al municipio, fundamenta la Sala del TSJ (Sentencia 5119/2010 de 23 de diciembre $\left.\mathrm{FJ} 5^{\circ} . \mathrm{b}\right)$ que «no habrá un atentado a la autonomía local sobre el diseño de la ciudad hecho por el municipio en la fase primigenia de la planificación urbanistica si el POTA, con los límites establecidos en el artículo 45 del Decreto, no acaba convirtiéndose en un límite de crecimiento sin respaldo en evaluación estratégica territorial sobre la planificación del municipio. Teniendo en cuenta que en esta evaluación estratégica no sólo se deben tener en consideración características económicas, territoriales, poblacionales, sostenibilidad de los recursos referidos al propio municipio, sino también los correspondientes al territorio en el que éste se integra. Por ello si la evaluación estratégica del plan urbanístico, con el respaldo de justificación y motivación de la sostenibilidad entendida como se hace en el ámbito de la normativa europea, incluyendo la medioambiental, aconseja un modelo de crecimiento que, justificadamente, supere este límite establecido en el artículo 45, la opción municipal se encontraba respaldada por los mismos criterios que han llevado al POTA a establecer unos límites genéricos de crecimiento y, en consecuencia, el mismo POTA permitiría la superación de este limite. Así se desprende de la propia dicción literal del artículo 45 en el aspecto controvertido».

Llegados a este punto debemos concluir donde comenzábamos éste epígrafe porqué en efecto, «en el POTA no se [decía ni] dice lo que dicen que [decía o] dice el POTA». Ni 
el artículo 45.4.a, ni la matemática, estricta, e ilógica, interpretación que desde los órganos llamados a aplicar la Norma se realizaba (avalada en cierta medida por las Instrucciones dictadas al efecto), justificaban ni justifican la afirmación de que el POTA contenga en la repetidamente mencionada Norma límites o barreras de crecimiento infranqueables, afirmación que encuentra fundamento tanto en la propia literalidad del artículo 45, como también hoy, en las de momento 3 consecutivas Sentencias del Tribunal Superior de Justicia de Andalucía.

\section{La modulación por el Decreto 11/2008 de los parámetros de crecimiento establecidos en el artículo 45 del POTA.}

Los enfrentamientos entre los municipios y la Administración autonómica derivados de la aplicación de los límites contenidos en la Norma 45 del POTA llevaron a que a finales de 2007 la Asamblea de la FAMP (Federación Andaluza de Municipios y Provincias aprobase una Resolución y a que en el marco de la negociación del llamado «Pacto por la Vivienda» lograran el compromiso de la administración autonómica de flexibilizar la interpretación del POTA para evitar el «encorsetamiento» urbanístico de los municipios, la negociación se centró en lograr que los municipios de menor población pudieran crecer por encima de los límites establecidos en la norma, es decir, el 30\% de la población y el 40\% del suelo urbanizable, pues se argumentaba "No es lo mismo analizar el 30\% de una ciudad grande que de un municipio de 2000 habitantes, donde hay que ampliar los límites de crecimiento». Además, de solicitar la creación de «escalones» para localidades con poblaciones de hasta 2.000 , hasta 5.000 y hasta 10.000 habitantes para modular los porcentajes del crecimiento, la Federación de municipios solicitaba que en el marco de la suavización de los criterios de aplicación del POTA, los suelos industriales quedasen fuera de esa limitación de crecimiento.

Fruto de esa negociación, se publica en el Boletín Oficial de la Junta de Andalucía de fecha 7 de febrero el Decreto 11/2008, de 22 de enero, por el que se desarrollan procedimientos dirigidos a poner suelo urbanizado en el mercado con destino preferente a la construcción de viviendas protegida. La Disposición adicional segunda de éste Decreto bajo el título «Desarrollo de los criterios básicos para el análisis y evaluación de la incidencia y coherencia de los planes generales de ordenación urbanística con el modelo de ciudad establecido en el Plan de Ordenación del Territorio de Andalucías recoge los frutos de la negociación mantenida, modulando y elevando las limitaciones al crecimiento hasta un $60 \%$ para municipios con menos de 2.000 habitantes, un 50\% para municipios entre 2.000 y 5.000 habitantes, y el 40\% para municipios entre 5.000 y 10.000 habitantes.

Nuevamente debemos poner de manifiesto nuestras dudas sobre la efectividad de los cambios operados ante las imprevisiones, imprecisiones e incluso contradicciones 
que la regulación reformada puede entrañar respecto de la regulación que se contiene en las Normas generales, señaladamente el POTA y la LOUA. De qué sirve sustraer del cómputo del límite máximo de crecimiento de los suelos urbanizables las superficies destinadas a suelo industrial. Acaso un fuerte crecimiento industrial no puede llevar aparejado también un crecimiento de la demanda y necesidades de suelo residencial que eventualmente podría no encontrar satisfacción por los límites que se imponen a los crecimientos de ésta última tipología de suelo. Y, no es más conforme con el concepto de ciudad compacta que se pretende y con los criterios de movilidad sostenible, que los usos industriales y los residenciales, con la necesaria zonificación, estén lo más próximos posibles para evitar desplazamientos innecesarios. De qué sirve que se modulen los límites para los municipios con crecimiento inferior en los últimos 10 años a la media de Andalucía $(10,2 \%$ ) que se establece en el apartado 2 primer párrafo de la Disposición adicional segunda, si el segundo párrafo permite ésta misma modulación para aquellos municipios que también hayan superado dicha media, a condición de que se garanticen las dotaciones, equipamientos, servicios e infraestructuras que establezca la legislación vigente, dotaciones equipamientos, servicios e infraestructuras que por otro lado son los establecidos con carácter general y a modo de estándares mínimos en el artículo 10 de la LOUA.

En cuanto a las actuaciones urbanísticas con destino mayoritario a vivienda protegida y en relación con el cómputo del número de habitantes por vivienda con un coeficiente inferior al marcado con carácter general en función de la tipología de las viviendas protegidas, dado que éste índice no ha sido contemplado con carácter general serán los distintos municipios los que lo establezcan en sus respectivos Planes y con carácter complementario al Decreto, la Orden de 29 de septiembre de 2008, por la que se regula el coeficiente aplicable para el cálculo de crecimiento poblacional derivado de las viviendas previstas en los instrumentos de planeamiento urbanístico, ha fijado en su artículo 1 dicho coeficiente en el 2,4 con carácter general sin consideración alguna a las peculiaridades turísticas o no de los municipios, a la existencia de más o menos viviendas de segunda residencia, etc., lo que no hace más que augurar la persistencia o la aparición de nuevas fuentes de conflicto en la aplicación de la norma. Finalmente el Decreto establece en su Disposición adicional segunda apartado $4^{\circ}$ la previsión de que la determinación del parámetro de crecimiento de población se referirá el dato de población existente para el conjunto de municipios de Andalucía al momento de la aprobación definitiva de la revisión o nueva redacción de cada Plan General de Ordenación Urbanística lo que significa la modificación del criterio mantenido en la Instrucción $1 / 2007^{17}$ de 10 de mayo de 2007 de

${ }^{17}$ La mencionada Instrucción establece en su epígrafe IV (ALCANCE Y CONTENIDO DEL INFORME DE INCIDENCIA) apartado 2 (Valoración de las determinaciones del planeamiento) letra A 
la Secretaría General de Ordenación del Territorio, relativa a la elaboración y tramitación de los informes de incidencia territorial de los Planes Generales de Ordenación Urbanística.

Pese a tener que constatar que el cambio de criterio resulta cuando menos más justo, ello no obstante no deja de plantear dudas, pues resulta muy difícil cuando no imposible la determinación en un Plan General que pasa por distintas fases en su proceso de formulación y aprobación (desde el Avance hasta la aprobación definitiva) y cuya tramitación puede demorarse bastantes años, cuál será la población en el momento de la aprobación definitiva para en función de la misma determinar los crecimientos urbanísticos que el Plan que se pretende aprobar ha de contemplar desde su fase inicial.

Puede comprenderse que la nueva regulación, pese a su intento de dar respuesta a las peticiones de flexibilidad realizada desde el municipalismo, genera más dudas que certezas, con lo que en poco puede ayudar a generar la seguridad jurídica y la necesaria templanza que debe presidir todo proceso de planificación urbana y sobre todo nuevamente se relega a un segundo plano la idea que debería ser el eje central de todo el proceso de alumbramiento de la planificación territorial y urbanística, a saber, la necesaria introducción de criterios de sostenibilidad que permitan tomar conciencia y poner freno a los procesos basados exclusivamente en un incremento exponencial de la huella urbanística y el «reto planteado de lograr un urbanismo capaz de seguir contribuyendo al progreso económico, sin olvidar los requerimientos del desarrollo urbano sostenible, es decir, entendiendo el suelo, además de como un recurso económico, como uno de los mas valiosos elementos naturales de los que disponemos, y en cuya regulación se hace preciso conjugar toda una serie de factores diversos: el medio ambiente, la calidad de vida, la eficiencia energética, la prestación de servicios, la cohesión social, etc.» ${ }^{18}$

El urbanismo se ha centrado hasta ahora fundamentalmente en la ordenación de los crecimientos urbanos sin considerar la existencia o no de un umbral máximo de crecimiento y sin cuestionarse siquiera el hecho de que no se puede crecer de forma indefinida. Ello explica que en los planeamientos que se han venido proyectando y

(Sistema de asentamientos) prescribía que para la comprobación que la dimensión del crecimiento urbanístico propuesto para un periodo de ocho años se ajusta a los parámetros establecidos en el apartado 4 de la norma 45 del Plan de Ordenación del Territorio de Andalucía, debía considerarse entre otros criterios el de que «la población existente será la correspondiente al Padrón Municipal de Habitantes en el momento de la aprobación inicial del Plans.

${ }^{18}$ Así se pone de manifiesto en el Libro blanco de la sostenibilidad en el planeamiento urbanístico español. Introducción, página 4.

Revista Andaluza de Administración Pública

ISSN: 0034-7639, núm. 81, Sevilla, septiembre-diciembre (2011), págs. 13-46 
aprobando, la cuestión de la «capacidad de carga» de un territorio ${ }^{19}$, no haya sido siquiera considerada para determinar la sostenibilidad de los mismos. Siendo fundamental la información sobre los umbrales a partir de los cuales la explotación o deterioro de los recursos naturales desemboca en pérdidas irreversibles, elemento que además resulta fundamental para poder establecer la capacidad de carga del territorio y regular los usos atendiendo al principio de precaución, ni los documentos más especializados de entre los que se integran en los Expedientes de planeamiento, los estudios de evaluación de impacto ambiental, han entrado a considerar la cuestión. A estos efectos puede resulta útil la información que puede ofrecer el concepto de «huella ecológicas de una ciudad ${ }^{20}$ que se refiere, básicamente a la extensión de terreno que una determinada ciudad precisa para mantener todas sus funciones productivas y vitales.

Resulta inevitable un cambio en la concepción de los Planes Urbanísticos, en los que más que someter sus directrices a artificiosos límites impuestos desde la Normativa de general cumplimiento, se establezcan dichos limites de forma clara y precisa con la suficiente flexibilidad como para que en función de las necesidades objetivas y razonables puedan ser superados sin alambicadas interpretaciones, y que antepongan como primer elemento de análisis de la capacidad o necesidad de crecimiento, la evaluación previa de la huella ecológica de la ciudad existente y el establecimiento de la capacidad de carga del territorio en el que se asienta la ciudad que se planifica así como las posibilidades de reutilización de suelos urbanos ya artificializados frente a las expectativas de poner en carga nuevos suelos. Perspectiva en la que en cumplimiento de las previsiones del artículo 46 del POTA $^{21}$ la Administración Autonómica tiene todavía mucho que decir formulando los criterios que favorezcan desarrollos urbanos basados en la recualificación de la ciudad existente.

${ }^{19}$ Para medir la capacidad de carga de un territorio se debe controlar el uso de los recursos asociados a los usos urbanos y los umbrales máximos de utilización que se puede hacer del sistema sin alterar de forma significativa su funcionamiento, considerando en el sistema tanto el uso de esos recursos, como la producción de residuos y la emisión de sustancias contaminantes, en último extremo, una zona urbana no debería exceder la capacidad de carga de su territorio próximo para ser sostenible.

${ }^{20}$ La huella de la ciudad comprende los materiales y la energía que utiliza directa e indirectamente. Se mide contabilizando el espacio necesario para obtener los recursos, para transformarlos y para utilizarlos o consumirlos, y depositar o asimilar sus residuos, repárese por ejemplo en el dato de que para que toda la población mundial pudiera vivir con el nivel de consumo de un americano medio, se precisaría una superficie equivalente a dos veces la del planeta Tierra.

${ }^{21} \mathrm{El}$ artículo 46 del POTA con carácter de directriz (D) establece con el título de ordenación y mejora de los procesos de urbanización que: «De acuerdo con los instrumentos previstos en la legislación urbanística, los órganos responsables de la política urbanística autonómica establecerán directrices y criterios relativos al tratamiento territorial y urbanístico de los procesos de urbanización característicos de Andalucía, en particular sobre todas o algunas las siguientes cuestiones: (...) h) Criterios para favorecer el diseño de políticas de desarrollos urbanos basados en la recualificación de la ciudad existente, y el aprovechamiento del suelo y el parque edificatorio». 


\section{LA LIMITACIÓN AL CRECIMIENTO COMO CRITERIO DE SOSTENIBILIDAD EN LA LEY DE SUELO ESTATAL}

La Disposición final segunda de la Ley 8/2007, de 28 de mayo, de Suelo, delegó en el Gobierno la potestad de dictar un Real Decreto Legislativo que refundiera el texto de ésta y los preceptos que aún quedaban vigentes del Real Decreto Legislativo 1/1992, de 26 de junio, por el que se aprobó el Texto Refundido de la Ley sobre Régimen del Suelo y Ordenación Urbana. El plazo para la promulgación de dicho texto refundido era de un año contado desde la entrada en vigor de la Ley de Suelo de 2007.

La tarea de refundición plantea dos objetivos básicos: por un lado aclarar, regularizar y armonizar la terminología y el contenido dispositivo de ambos textos legales, y por otro lado estructurar y ordenar en una única disposición general una serie de preceptos dispersos y de diferente naturaleza, procedentes del Texto Refundido de 1992, dentro de los nuevos contenidos de la Ley de Suelo de 2007, adaptados a las competencias urbanísticas, de ordenación del territorio y de vivienda de las Comunidades Autónomas. Se pretende con ello evitar la dispersión de la distinta normativa y el fraccionamiento de las disposiciones que recogen la legislación estatal en la materia, excepción hecha de la parte vigente del Real Decreto 1346/1976, de 9 de abril, por el que se aprueba el Texto Refundido de la Ley sobre Régimen del Suelo y Ordenación Urbana, que tiene una aplicación supletoria salvo en los territorios de las Ciudades de Ceuta y Melilla y, en consecuencia, queda fuera del marco de la delegación legislativa en cuya virtud se aprueba el Real Decreto Legislativo 2/2008, de 20 de junio, por el que se aprueba el texto refundido de la ley de suelo.

\section{La incorporación de criterios de sostenibilidad en la regula- ción estatal del régimen de suelo}

La nueva regulación estatal constituida por la Ley 8/2007 y la refundición de la misma con la legislación urbanística vigente operada mediante la LS-2008, pretende desplazar la tradicional concepción desarrollista impulsora de un crecimiento urbano ilimitado por otra que lo controle, insistiendo en la regeneración de la ciudad existente, frente a las nuevas transformaciones de suelo. La Exposición de Motivos de la LS-2008 se apoya expresamente en la Estrategia Territorial Europea y en la Comunicación de la Comisión sobre una estrategia temática para el medio ambiente urbano, proponiendo un modelo de ciudad compacta y advirtiendo de los graves inconvenientes de la urbanización dispersa y desordenada». ${ }^{22}$

\footnotetext{
${ }^{22}$ En la Exposición de Motivos de la LS-2008 podemos leer «el crecimiento urbano sigue siendo necesario, pero hoy parece asimismo claro que el urbanismo debe responder a los requerimientos de un desarrollo sostenible, minimizando
} 
Desde sus primeros líneas la LS-2008 hace patente su apuesta por el desarrollo sostenible estableciendo que las políticas relativas a la regulación, ordenación, ocupación, transformación y uso del suelo tienen deben que hacer posible el uso racional de los recursos naturales armonizando los requerimientos de la economía, el empleo, la cohesión social, la igualdad de trato y de oportunidades entre mujeres y hombres, la salud y la seguridad de las personas y la protección del medio ambiente, contribuyendo a la prevención y reducción de la contaminación.

En particular la LS-2008 viene a establecer que las políticas públicas deberán procurar la eficacia de las medidas de conservación y mejora de la naturaleza, la flora y la fauna y de la protección del patrimonio cultural y del paisaje, la protección, adecuada a su carácter, del medio rural y la preservación de los valores del suelo innecesario o no idóneo para atender las necesidades de transformación urbanística y conseguir un medio urbano en el que la ocupación del suelo sea eficiente, que esté suficientemente dotado por las infraestructuras y los servicios que le son propios y en el que los usos se combinen de forma funcional y se implanten efectivamente, cuando cumplan una función social aunque reconoce que la consecución de éstos fines debe adaptarse a las peculiaridades que resulten del modelo territorial adoptado en cada caso por los poderes públicos competentes en materia de ordenación territorial y urbanística.

En resumen con MENÉNDEZ REXACH ${ }^{23}$ podemos decir que «la afirmación en la LSO8 del principio de desarrollo territorial y urbano sostenible como inspirador de un «modelo territorials cuy a definición compete a las administraciones autonómicas y municipales tiene, al menos, las siguientes implicaciones: a) una cierta recuperación de la discrecionalidad del planeamiento frente a la concepción estática de la clasificación del suelo en la LS98; b) que la definición de ese «modelo» territorial tiene un componente ambiental imprescindible en cuanto debe ser «sostenible»; c) que las exigencias de ese principio serán diferentes, en función de las circunstancias, pero se deben acreditar en la documentación de los instrumentos de ordenación territorial y urbanística y, por tanto, ser debatidas, en el proceso de elaboración de los planes con la participación de los afectados.»

Sin embargo nos interesa ahora del Texto Refundido de forma específica por la conexión que tiene con el concreto objeto del presente trabajo, la regulación conte-

el impacto de aquel crecimiento y apostando por la regeneración de la ciudad existente. La Unión Europea insiste claramente en ello, por ejemplo en la Estrategia Territorial Europea o en la más reciente Comunicación de la Comisión sobre una Estrategia Temática para el Medio Ambiente Urbano, para lo que propone un modelo de ciudad compacta y advierte de los graves inconvenientes de la urbanización dispersa o desordenada: impacto ambiental, segregación social e ineficiencia económica por los elevados costes energéticos, de construcción y mantenimiento de infraestructuras y de prestación de los servicios públicos».

${ }^{23}$ MENÉNDEZ REXACH, Ángel (2009): «Urbanismo sostenible y clasificación del suelo: legislación estatal y autonómica». Revista catalana de dret públic. Número 38. 2009, página 142. 
nida en la Disposición Transitoria $4^{\text {a }}$ en relación con lo establecido en el artículo 15.6 del Real Decreto Legislativo 2/2008 (en adelante LS-2008).

El artículo 15 de la LS-2008 que encabeza con el título de «Evaluación y seguimiento de la sostenibilidad del desarrollo urbano» dispone en su apartado 6 lo siguiente: "La legislación sobre ordenación territorial y urbanística establecerá en qué casos el impacto de una actuación de urbanización obliga a ejercer de forma plena la potestad de ordenación del municipio o del ámbito territorial superior en que se integre, por trascender del concreto ámbito de la actuación los efectos significativos que genera la misma en el medio ambientes. Por su parte, en previsión de una eventual ausencia de regulación autonómica que pueda frustrar los objetivos que se pretenden con la regulación del artículo 15.6, y por tanto con evidente intención de constituir una legislación más supletoria que transitoria, la Disposición Transitoria $4^{\mathrm{a}}$ de la LS-2008 establece que: «Si, transcurrido un año desde la entrada en vigor de la Ley 8/2007, de 28 de mayo, de Suelo, la legislación sobre ordenación territorial y urbanística no estableciera en qué casos el impacto de una actuación de urbanización obliga a ejercer de forma plena la potestad de ordenación, esta nueva ordenación o revisión será necesaria cuando la actuación conlleve, por sí misma o en unión de las aprobadas en los dos últimos años, un incremento superior al 20 por ciento de la población o de la superficie de suelo urbanizado del municipio o ámbito territoriabr. En síntesis pues, la Disposición Transitoria $4^{\text {a }}$ de la LS-2008 resultará o no de aplicación en Andalucía dependiendo de que pueda deducirse del ordenamiento de nuestra Comunidad que ya se contemplan normas equivalentes a las que el artículo 15.6 establece para determinar los casos en que una actuación de urbanización obliga a ejercer de forma plena la potestad de ordenación urbanística.

Antes de proseguir conviene recordar que el artículo 15 y la Disposición transitoria $4^{\text {a }}$ de la LS-2008 son reproducción literal de los artículos 15 y de la Disposición transitoria $4^{a}$ de la Ley $8 / 2007$ y que contra la misma y en concreto contra dicho artículo y Disposición transitoria se presentaron y se encuentran en trámite los siguientes Recursos de inconstitucionalidad: 1) Recurso de inconstitucionalidad Número 6963-2007 promovido por el Consejo de Gobierno de la Comunidad de Madrid, contra los artículos 6 a), 10 b), 11.2, 15, 16.1.b) y 34, disposiciones adicionales $1^{\text {a }}$ y $9^{a}$ y disposición transitoria $4^{a}$ de la Ley 8/2007, de 28 de mayo (BOE núm. 241 de 8 de octubre de 2007). 2) Recurso de inconstitucionalidad Número 6964-2007 promovido por el Consejo de Gobierno de La Rioja, contra los artículos 1, 2, 10, 11.2, 15.6, 17.5) y 33 , disposición $6^{\mathrm{a}}$, apartado 1 , y disposición transitoria $1^{\mathrm{a}}$ y final $1^{\mathrm{a}}$ de la Ley 8/2007, de 28 de mayo (BOE núm. 241 de 8 de octubre de 2007) y, 3) Recurso de inconstitucionalidad Número 6973-2007 promovido por el Gobierno de Canarias contra los artículos 1, 2.2, 3.1, 6, 8.1 último párrafo, 9.3, 10.a) y b), 11.2, 4 y 5, 14.1, 15.3, 4 y 5, 16.1.c) de la Ley 8/2007, de 28 de mayo, disposición adicional $1^{\mathrm{a}}$, transitoria $2^{\mathrm{a}}$ y $4^{a}$ y disposición final $1^{\mathrm{a}}$ apartado $1^{\circ}$. 


\section{La adaptación de la legislación territorial y urbanística de las distintas Comunidades Autónomas a las exigencias derivadas del artículo 15.6 de la Ley de Suelo}

Publicada la Ley 8/2007 y el Texto Refundido de la LS-2008, muchos autores hicieron explícita su opinión del escaso recorrido legislativo que ésta Disposición Transitoria $4^{a}$ podía tener en su necesaria incorporación al ordenamiento territorial y urbanístico de las distintas Comunidades Autónomas, pues como pusiera de relieve SÁNCHEZ GOYANES ${ }^{24}$ "cabe aventurar que, habiendo incorporado la totalidad de los Derechos Urbanísticos autonómicos la tradicional diferenciación entre un supuesto u otro de alteración del planeamiento, la cual y a habia interiorizado, obviamente, como uno de los factores conducentes al distinto régimen de uno y otro, el mayor o menor impacto ambiental potencialmente generado, la precitada Disposición Transitoria puede perfectamente quedar inédita. A mayor abundamiento, en gran medida, el Derecho autonómico, tributario en esto del histórico estatal, ha positivado la doctrina jurisprudencial en la materia, cuya última actualización la constituye la batería de Sentencias del Tribunal Supremo anulatoria de otras tantas Modificaciones Puntuales del Plan General de San Sebastián de los Reyes (Madrid) porque encubrían una revisión global de la ordenación preexistente sin seguir el cauce procedimental propio para ella, más riguroso precisamente para salvaguardar objetivos como el de la armonización con los requerimientos de la protección ambiental».

Pocas voces se han cuestionado la necesidad o procedencia de la adaptación de las respectivas legislaciones territoriales y/o urbanísticas a las exigencias derivadas de la regulación contenida en el artículo 15.6 y disposición transitoria cuarta de la Ley 8/2007 y un año después del mismo artículo y disposición transitoria incorporada al Texto Refundido de la LS-2008, o se ha asumido como un hecho ineludible la necesidad de adaptación, ó siguiendo en éste punto a SÁNCHEZ GOYANES, se ha considerado como innecesaria dicha adaptación al establecer las legislaciones autonómicas de forma precisa los casos y supuestos en los que una alteración del planeamiento obliga al ejercicio pleno de las potestades de ordenación, y en qué supuestos bastará con la simple modificación del instrumento urbanístico.

Así podemos comprobar cómo en éste punto la actividad legislativa de las distintas administraciones autónomas ha sido desigual y con desigual resultado. Siguiendo en éste punto a VERA JURADO ${ }^{25}$ y más de un año después de que hiciera pública su opinión, podemos sintetizar la actividad legislativa de las distintas CC.AA. seña-

${ }^{24}$ SÁNCHEZ GOYANES, Enrique (2009): «Ley del Suelo. Comentario sistemático del Texto Refundido de 2008». Editorial LA LEY. Madrid. 2009, páginas 574-614 y páginas 1270-1273.

25 VERA JURADO, Diego J. (2010): «Los límites del crecimiento: la aplicación de la disposición transitoria cuarta del Real Decreto Legislativo 2/2008, de 20 de junio, por el que se aprueba el Texto Refundido de la Ley de Suelo». Revista de Administración Pública. Número 181. Enero-Abril de 2010, páginas 
lando que $\leftarrow$ La mayoría de las Comunidades Autónomas, un año después de haber entrado en vigor, no han aprobado normas de adaptación de la Ley de Suelo estatal, y algunas, que si han aprobado tales normas, obvian lo dispuesto en el artículo 15.6 (Islas Baleares, Valencia). - Es regla general que no conoce excepciones en las adaptaciones legislativas aprobadas identificar la «actuación de urbanización, a que se refiere el artículo 15.6, con la prevista en un instrumento de modificación o de innovación del planeamiento general. - Para alguna Comunidad Autónoma - caso de Cataluñ - la adaptación de su legislación urbanistica al artículo 15.6, le ha llevado a incorporar como causa de revisión la fijación de nuevos criterios que afecten al modelo territorial, recobrando así una previsión semejante a la que establece la LOUA entre nosotros, mientras otra Comunidad Autónoma, como el País Vasco, se adapta especificando los supuestos en que debe entenderse afectado el modelo territorial.»

\section{La necesidad o procedencia de la adaptación de la legislación territorial y urbanística en el caso de Andalucía}

Puntualiza en primer lugar VERA JURADO ${ }^{26}$ que en cuando al término «legislación» que se emplea por el legislador en el artículo 15 y en la disposición transitoria $4^{\mathrm{a}}$ de la LS-2008, ha de entenderse referido a su concepto material, lo que implica que no se requiere necesariamente que los supuestos en que ley en sentido formal sino que la referencia a la «legislación territorial o urbanistica» ha de entenderse realizada al conjunto de las normas que con distinto rango pueda integrar el corpus normativo establecido por cada Comunidad Autónoma en éste concreto campo del ordenamiento.

Ciñendo el análisis al específico contenido del artículo 15.6 de la LS-2008, VERA $\mathrm{JURADO}^{27}$ expone que a su juicio «Para el legislador estatal es básico que la legislación de ordenación territorial y urbanística establezca los casos en que procede ejercer de forma plena la potestad de ordenación, en atención a actuaciones de urbanización que tengan cierta trascendencia y que generan efectos significativos en el medio ambiente y los recursos naturales. Lo que se prescribe para

407-425. El autor en el trabajo reseñado realiza un extenso análisis de la recepción legislativa que las distintas Comunidades Autónomas realizaron en su normativa territorial y urbanística de las previsiones del artículo 15 de la LS-2008. Más de un año después de la publicación de éste estudio, con ligeras matizaciones, no se alteran las conclusiones que de ésta cuestión se exponen en el trabajo publicado.

${ }^{26}$ VERA JURADO, Diego J. (2010): 411. El autor apoya su afirmación en la numerosa jurisprudencia del Tribunal Constitucional de entre la que cita la STC 81/2003, en la que el Alto Tribunal afirma que, "cuando de lo que se trata es de indagar el significado con que el vocablo «legislación» se utiliza este Tribunal ha declarado que el que prevalece es el concepto material, y no el formal constreñido a las Leyes, en la acepción de normas que emanan de quienes ostentan el poder legislativo, o de quienes por excepción o por delegación, pueden producir normas con valor de Ley (STC 39/1982), debiendo por tanto dejarse ya sentado que el concepto de legislación es un concepto que debe ser entendido en sentido material (STC 35/1989) (Ff.5)».

27 VERA JURADO, Diego J. (2010): 413-414.

Revista Andaluza de Administración Pública

ISSN: 0034-7639, núm. 81, Sevilla, septiembre-diciembre (2011), págs. 13-46 
las instancias competentes es, pues, que incorporen a sus respectivas legislaciones una causa de revisión del planeamiento, referida a los nuevos desarrollos urbanísticos o, en definitiva, al crecimiento.»

En éste contexto no puede cuestionarse la íntima conexión que la previsión normativa tiene con el desarrollo sostenible, sobre todo si consideramos la experiencia de los últimos años de los desarrollos urbanísticos promovidos al margen de cualquier raciocinio y en virtud de los cuales un promotor con la exclusiva finalidad de obtener el máximo beneficio particular mediante un uso abusivo de las modificaciones puntuales del planeamiento conseguía la correspondiente autorización en un Municipio para convertir en nuevo suelo urbanizable suelos rústicos con superficies equivalentes a varias veces la preexistente. ${ }^{28}$

La introducción de la enmienda que incorporó el apartado 6 al artículo 15 en la tramitación del proyecto de Ley en el Congreso de los Diputados responde al propósito de atajar la posibilidad de que a través de sucesivas modificaciones un planeamiento urbanístico perfilar con más nitidez los límites que harían necesaria la revisión del modelo urbanístico inicialmente adoptado. ${ }^{29}$

El conocimiento de los antecedentes que han llevado al legislador a establecer la regulación que comentamos nos ayuda a delimitar su ámbito de aplicación, ámbito que, igual que sucede con la disposición transitoria $4^{\mathrm{a}}$, se refiere al crecimiento propuesto en «una actuación de urbanización», lo que comprendería la ordenación o creación de una nueva urbanización en lo que el Planeamiento calificada hasta entonces como suelo no urbanizable pues resulta dificil imaginar que una actuación urbanizadora pueda alterar el modelo territorial definido en la ordenación general, si ya estaba prevista y justificada como parte de esa ordenación general, distinto es el caso de que hayan cambiado sustancialmente las circunstancias conforme a las que se efectúo la inicial previsión, porque éste supuesto abocaría a la aplicación de una causa de revisión que por lo demás, es típica encontrar en la mayoría de los ordenamientos territoriales y urbanísticos.

\footnotetext{
${ }^{28}$ El noticiado ejemplo de Seseña (Toledo) que con una población, de 8.000 habitantes aprueba proyectos que multiplican por 5 veces la población prevista es ilustrativo de ésta afirmación.

${ }^{29}$ Como puede leerse en el BOLETÍN OFICIAL DE LAS CORTES GENERALES (VIII LEGISLATURA). Serie A: PROYECTOS DE LEY. 1 de diciembre de 2006. Núm. 96-9, página 106, la enmienda número 242 firmada por el Grupo parlamentario Socialista del Congreso por la que se proponía la adición del apartado 6 al artículo 15 motivaba dicha incorporación en los siguientes términos «El Proyecto de Ley hace una apuesta por la participación efectiva y por la sostenibilidad de los desarrollos urbanísticos. Pero tanto la participación de los ciudadanos en el procedimiento como la evaluación ambiental de los planes quedan defraudados si se permite que sigan aprobándose grandes actuaciones de urbanización mediante modificaciones puntuales de los planes, sin la necesaria visión de conjunto de su impacto sobre la economía y el territorio locales. Un precepto de estas características se muestra a todas luces necesario, vista la alarma social generada por algunas actuaciones urbanisticas recientes. Su incidencia sobre el modelo urbanístico de las CC.AA. es mínima, ya que sólo establece un estándar mínimo absoluto y deja en manos autonómicas la determinación de los casos y el procedimiento para la revisión de los planes».
} 
Llegados a éste punto debemos constatar que la legislación urbanística de nuestra Comunidad tiene perfectamente establecidos los supuestos cuya concurrencia determinarían el ejercicio pleno de las potestades urbanísticas. Para nuestra legislación urbanística y conforme dispone el artículo 37.1 de la LOUA «Se entiende por revisión de los instrumentos de planeamiento la alteración integral de la ordenación establecida por los mismos, y en todo caso la alteración sustancial de la ordenación estructural de los Planes Generales de Ordenación Urbanistica», estableciendo en su apartado 3 que «Los instrumentos de planeamiento se revisarán en los plazos que ellos mismos establezcan y cuando se produzcan los supuestos o circunstancias que prevean a tal efecto», previsión que se completa con el deslinde conceptual entre revisión y modificación al establecer el artículo 38.1 del mismo texto legal que «Toda alteración de la ordenación establecida por los instrumentos de planeamiento no contemplada en el artículo anterior se entenderá como modificacións.

Tras examinar la doctrina jurisprudencial del Tribunal Supremo VERA JURA$\mathrm{DO}^{30}$ concluye «parece indudable entre la previsión del artículo 15.6 de la nueva Ley de Suelo estatal y la del artículo 37.1 de la LOUA hay bastante en común. Del ámbito de aplicación de este último, en rigor no cabe excluir la obligación de revisar -de ejercer de forma plena la potestad de ordenación- ante una determinada actuación de urbanización que pretenda habilitarse mediante una innovación. Y tampoco cabe excluir, como acaba de verse, el caso de las modificaciones o innovaciones sucesivas, pues el efecto de acumulación - al que se refiere la Disposición Transitoria $4^{a}$ - también forma parte del campo de aplicación del artículo 37». Para el autor «contribuyen a reforzar el paralelismo entre el artículo 15.6 de la LSO8 y la causa de revisión de la LOUA, «alteración sustancial de la ordenación estructural, los términos en que se expresa la exposición de motivos de la Ley de Suelo, al identificar la problemática, como antes se ha visto, con «las actuaciones urbanizadoras de mayor envergadura e impacto, que producen una mutación radical del modelo territorials. Desde luego, con la sola herramienta del artículo 37.1 de la LOUA, sería necesaria la revisión ante una innovación que, teniendo por objeto clasificar nuevo suelo urbanizable o alterar al alza sus condiciones de transformación, afectara radicalmente al modelo territorial. Que ambos preceptos vienen a requerir una consecuencia semejante -la revisión - ante un presupuesto en principio también semejante - una o varias operaciones urbanísticas con entidad relevante-, podría explicarse en la circunstancia de que algunas Comunidades Autónomas habian eliminado de sus respectivas legislaciones el supuesto clásico de revisión que hoy refiere el artículo 37.1 de la LOUA» por lo que concluye que todo «apunta a que, efectivamente, entre las previsiones del artículo 15.6 de la LSO8 y las del 37.1 de la LOUA existe identidad de razóns.

La conclusión a la que todo lo argumentado conduce es pues lógica, la Disposición Transitoria $4^{\mathrm{a}}$ no es aplicable en Andalucía en lo que respecta a modificaciones o innovaciones del instrumento general.

${ }^{30}$ VERA JURADO, Diego J. (2010): 419-420.

Revista Andaluza de Administración Pública

ISSN: 0034-7639, núm. 81, Sevilla, septiembre-diciembre (2011), págs. 13-46 


\section{La sostenibilidad como paradigma de la legislación territorial y urbanística en Andalucía y la innecesariedad de su adapta- ción a la Ley Estatal de Suelo en éste extremo}

El criterio de la sostenibilidad, como hilo conductor de la normativa de ordenación territorial y urbanística en nuestra Comunidad Autónoma, se hace ya visible desde la propia Exposición de Motivos de la LOUA que no se recata en afirmar que se trata de una Ley que apuesta por la calidad de vida de los ciudadanos y de las ciudades y en tal sentido también una Ley que apuesta por el desarrollo sostenible para declarar acto seguido que "El uso racional y sostenible de los recursos naturales, la protección del medio ambiente y del paisaje y específicamente la protección y adecuada utilización del litoral constituyen fines especificos, también, de esta Ley. Tales principios son instrumentados a lo largo de su texto, desde el objeto y contenidos básicos de los planes urbanísticos, a la clasificación de los suelos, o a la tipificación de las infracciones y sanciones»

Respecto a los instrumentos de planeamiento proclama la Exposición de Motivos de la LOUA que se ha hecho un esfuerzo para precisar los criterios por los que determinados terrenos deben ser excluidos del proceso urbanizador a través de su clasificación como suelo no urbanizable, quedado facultado el Plan General para establecer dentro de ésta clasificación distintas categorías y señalando que son los criterios de sostenibilidad, crecimiento racional y ordenado de la ciudad así como las propias características estructurales del municipio los elementos que habrán de determinar el que determinados suelos se clasifiquen como no urbanizable. Ya en su texto articulado, declara el artículo 3.1.a de la LOUA que constituye uno de los fines de la actividad urbanística "conseguir un desarrollo sostenible y cohesionado de las ciudades y del territorio en términos sociales, culturales, económicos y ambientales, con el objetivo fundamental de mantener y mejorar las condiciones de calidad de vida en Andalucia» así como el «Vincular los usos del suelo a la utilización racional y sostenible de los recursos naturales» (artículo 3.1.b).

En cuanto a la ordenación urbanística establecida en los instrumentos de planeamiento, en el marco de la ordenación del territorio, declara la LOUA que su objeto será en todo caso "La incorporación de objetivos de sostenibilidad que permitan mantener la capacidad productiva del territorio, la estabilidad de los sistemas naturales, mejorar la calidad ambiental, preservar la diversidad biológica, y asegurar la protección y mejora del paisajes. El sometimiento del planeamiento municipal a la ordenación territorial se reafirma al señalar el artículo 8.1 de la LOUA que "Los Planes Generales de Ordenación Urbanística establecen, en el marco de los Planes de Ordenación del Territorio, la ordenación urbanística en la totalidad del término municipal y organizan la gestión de su ejecución, de acuerdo a las características del municipio y los procesos de ocupación y utilización del suelo actuales y previsibles a medio plazo» sometimiento del planeamiento municipal al territorial que se refuerza en el artículo 9.1.A.a al establecer que en el marco de los fines y objetivos enumerados en el artículo 3 y, en su 
caso, de las determinaciones de los Planes de Ordenación del Territorio, los Planes Generales de Ordenación Urbanística deben optar por el modelo y soluciones de ordenación que mejor aseguren «Su adecuada integración en la ordenación dispuesta por los Planes de Ordenación del Territorios.

Los recordatorios del articulado de la LOUA a los criterios de sostenibilidad, se completan con la previsión respecto a los Planes de Sectorización para los que se prescribe que valorarán la ordenación que en los mismos se contengan en razón de "La coherencia de sus determinaciones con las estrategias globales regionales y municipales para la utilización racional y sostenible del suelo» (artículo 12.3.a); con las referencias que el artículo 46.1.k realiza al Suelo No Urbanizable señalando que pertenecen al suelo no urbanizable los terrenos que el Plan General de Ordenación Urbanística adscriba a esta clase de suelo por «Ser improcedente su transformación teniendo en cuenta razones de sostenibilidad, racionalidad y las condiciones estructurales del municipion; las menciones que el artículo 47.c realiza al Suelo Urbanizable sectorizado para el que dispone que esta categoría de suelo «deberá tener en cuenta las características naturales y estructurales del municipio, así como la capacidad de integración de los usos del suelo y las exigencias de su crecimiento racional, proporcionado y sosteniblen; referencias todas ellas que completa el artículo 50.C.a estableciendo que forma parte del contenido urbanístico legal del derecho de propiedad del suelo, cuando se trate de suelo urbanizable no sectorizado, además de los derechos propios del suelo urbanizable «El de formular al municipio la consulta sobre la viabilidad de transformación de sus terrenos, en función de su adecuación al modelo de crecimiento urbano del municipio, a las condiciones y previsiones para su sectorización, y a su idoneidad para la producción de un desarrollo urbanístico ordenado, racional y sostenible».

Las remisiones que la LOUA realiza a la planificación territorial, estableciendo sin ningún género de dudas la vinculación y sometimiento a la misma de la planificación municipal, nos remite a la consideración de todo el corpus legislativo que integra en nuestra Comunidad Autónoma la ordenación del territorio y que forman conjuntamente con la legislación urbanística el referente de obligado cumplimiento y contraste con la normativa estatal a los fines de considerar la adecuación de nuestro ordenamiento a los mandatos derivados de ésta, fundamentalmente en cuanto se refiere a la consideración de la correcta incorporación a nuestra normativa propia de los criterios de sostenibilidad y singularmente al cumplimiento del mandato derivado del artículo 15.6 y disposición transitoria $4^{\text {a }}$ de la LS-2008. Y es que la propia mención del artículo 15.6 «La legislación sobre ordenación territorial y urbanística establecerá ....» o la de la Disposición Transitoria $4^{\text {a }}$ de la LS-2008 «Si, transcurrido un año desde la entrada en vigor de la Ley 8/2007, de 28 de mayo, de Suelo, la legislación sobre ordenación territorial y urbanística no estableciera en qué casos (...)» fuerzan a que el juicio de adaptación de la legislación autonómica a las previsiones del mencionado artículo y disposición, deba rea- 
lizarse no sólo a la luz de la regulación contenida en la legislación sobre ordenación urbanística sino también y singularmente sobre la legislación sobre la ordenación territorial.

Es en éste sentido que podemos afirmar que en nuestra Comunidad constituye un referente y paradigma de la incorporación de los criterios de sostenibilidad y del cumplimiento de la regulación estatal de la LS-2008, todo el marco normativo que integra la legislación sobre ordenación territorial entre la que debemos destacar la LOTA, el POTA, los distintos Planes subregionales que en los últimos años han venido formulándose y aprobándose, el Decreto 11/2008, y la LOUA pero, como ha venido a destacar VERA JURADO ${ }^{31}$ «A diferencia de la LOUA, en la que la sostenibilidad queda prácticamente confiada al planeamiento, el POTA inaugura un escenario hasta entonces desconocido. Se manifiesta en reglas precisas y por lo general unívocas; podría afirmarse que el POTA establece determinaciones materiales de ordenación, al modo de los estándares tradicionales conforme a los que se han definido los deberes de cesión de suelos con uso dotacional, bien que referidas en este caso al crecimiento, a la manera en que debe producirse la expansión urbana. Además, el artículo 45 regula detalladamente la forma en que debe determinarse el crecimiento e incluso prohíbe con carácter general la previsión de crecimientos por encima del 40 por 100 del suelo urbano y del 30 por 100 de la población en un horizonte de 8 años»

$\mathrm{Ni}$ en éstos casos ni cuando el propio POTA prioriza la intervención en la ciudad consolidada sobre los nuevos desarrollos se limita a imponer una mera regla de carácter formal de la clase de la prevista en el artículo 15.6 pues como pone de manifiesto VERAJURADO 32 "Criterios materiales o determinaciones propiamente dichas pueden verse a lo largo de los demás artículos de la Sección $4^{a}$ (46 a 61), en lo que evidentemente responde a la estrategia de «definir los modelos de ciudad que deben ser tenidos en cuenta por el planeamiento urbanistico y territorial, para consolidar las redes del Sistema de Ciudades y preservar los valores ecológicos y ambientales del entorno» (artículo 44.1)». Lo anterior lleva a VERA JURADO a tener que afirmar que «en verdad, el POTA está definiendo un modelo de ciudad, en el que se insertan y con el que deben mostrar coherencia la generalidad de los municipios. El modelo puede ser diverso y más o menos impreciso pero la preocupación por el crecimiento pasa a ser el principal cometido de esta planificación territorials.

Para SÁNCHEZ GOYANES ${ }^{33}$ en realidad el artículo 15.6 LS-2008 «simplemente, se remite a la legislación autonómica, para que sea ésta la que distinga los casos en que se estará ante «revisión» 0 «modificación»y, consiguientemente someta a los primeros al procedimiento administrativo más complejo, especialmente para someterlo a la evaluación ambiental previà.

\footnotetext{
31 VERA JURADO, Diego J. (2010): 422-423.

${ }^{32}$ VERA JURADO, Diego J. (2010): 423.

33 SÁNCHEZ GOYANES, Enrique (2009): 613.
} 
Incluso en ésta hipótesis no podemos desconocer que en nuestra Comunidad Autónoma se encuentra vigente la Ley 7/2007 de 9 de julio, de Gestión Integrada de la Calidad Ambiental cuyo artículo 36.1.c) somete a Evaluación de Impacto Ambiental los instrumentos de Planeamiento Urbanístico estableciendo su Anexo I ${ }^{34}$ un sistema mediante el cual se someten a Evaluación Ambiental los «Panes Generales de Ordenación Urbanística, así como las innovaciones que afecten al suelo no urbanizable» (epígrafe 12.3); los "Planes de Ordenación Intermunicipal así como sus innovaciones» (epígrafe 12.4); los "Planes Especiales que puedan afectar al suelo no urbanizable» (epígrafe 12.5); los «Planes de sectorización» (epígrafe 12.6); y finalmente los "Planes de desarrollo del planeamiento general urbanístico cuando éste último no haya sido objeto de evaluación de impacto ambientaly (epígrafe 12.7). Ningún instrumento escapa a la necesidad de efectuar el trámite de Evaluación Ambiental.

Y finalmente, la propia Administración Autonómica en la reciente "Estrategia Andaluza de Sostenibilidad Urbana», aprobada por Acuerdo del Consejo de gobierno del 3 de mayo de $2011^{35}$ asume y presume de la incorporación de los criterios de sostenibilidad en la ordenación territorial y urbanística de nuestra Comunidad y al constatar que «se vienen realizando desarrollos urbanos que emulan principios importados de otras latitudes y que, en buena lógica, no están adaptados a las condiciones ambientales y culturales de Andalucía. La actual situación de crisis ha evidenciado este proceso y está demostrando que el modelo económico que ha seguido España y Andalucía no es el deseable. Este modelo ha posibilitado el desarrollo de sistemas urbanos caracterizados por el consumo elevado de suelo y la configuración de una ciudad difusa y altamente dependiente de un creciente nivel de consumo de recursos naturales de todo tipo» manifiesta que ante éstos procesos el POTA «a través de sus normas y directrices relativas al control de los procesos de urbanización, incide claramente en esta problemática, ofreciendo instrumentos para la consolidación de un modelo de ciudad compacta, que se ve reforzado por la planificación de ámbito subregional, la cooperación territorial y la presente estrategia». Todo lo que nos lleva a considerar como lo hace VERA JURADO ${ }^{36}$ que «en resumidas cuentas, todo el sistema de ordenación y control territorial descrito hasta este momento hace difícil afirmar que Andalucía no cumple con los requisitos ambientales y territoriales requeridos por el artículo 15.6 de la Ley de Suelo. Se puede afirmar que la situación que presenta la Comunidad Autónoma de Andalucía en el desarrollo de los instrumentos y parámetros de ordenación territorial no tiene parangón con

\footnotetext{
34 Anexo modificado por Decreto 356/2010, de 3 de agosto, por el que se regula la autorización ambiental unificada, se establece el régimen de organización y funcionamiento del registro de autorizaciones de actuaciones sometidas a los instrumentos de prevención y control ambiental, de las actividades potencialmente contaminadoras de la atmósfera y de las instalaciones que emiten compuestos orgánicos volátiles, y se modifica el contenido del Anexo I de la Ley 7/2007, de 9 de julio, de Gestión Integrada de la Calidad Ambiental.

35 Publicada en el Boletín Oficial de la Junta de Andalucía número 97 del 19 de mayo de 2011.

36 VERA JURADO, Diego J. (2010): 425.
} 
el resto de las comunidades autónomas, que, en muchos casos, presentan una situación de debilidad normativa que no permite una respuesta certera al contenido del artículo 15.6 de la Ley de Suelo. La interpretación del ordenamiento jurídico es, en suma, una labor de interrelación de objetivos y medios. Pretender aplicar en el ámbito de Comunidad Autónoma de Andalucía la Disposición Transitoria 4 de la LSO8 es desconocer toda la actividad normativa realizada hasta el momento y, aun algo peor, es añadir al sistema de protección ambiental y sostenibilidad un elemento de incertidumbre e incoherencia no deseado por el legislador estatal».

\section{CONCLUSIONES}

Como se ha puesto de relieve en las páginas precedentes, la creciente preocupación e importancia que todos los aspectos relacionados con la protección del medio ambiente han supuesto la evolución de las políticas de ordenación territorial y urbanística hasta que finalmente se ha llegado a admitir de forma pacífica por la doctrina, que los Planes de Ordenación del Territorio y las prescripciones de la legislación Urbanística constituyen instrumentos de suma importancia para conseguir muchos de los objetivos más importantes de la prevención ambiental, desde la selección de los suelos susceptibles de integrar el proceso de planificación y transformación urbanística hasta el propio modo de realización de la urbanización de los suelos e incluso de la edificación sobre los mismos. Lo anterior explica que el Medio Ambiente pueda hoy ser considerado más que una política concreta un sistema capaz de reconducir a la unidad todos los elementos que lo integran, características que explican que el Medio Ambiente tenga una vocación horizontal o transversal capaz de incidir en todos los ámbitos del ordenamiento jurídico.

En ésta perspectiva de horizontalidad o transversalidad de las políticas de protección del medio ambiente, su incidencia el marzo de las normas sobre ordenación del territorio y urbanismo se justifica y manifiesta, entre otros extremos en la necesidad de limitar los crecimientos urbanísticos ante la constatación de la insostenibilidad ambiental de los modelos territoriales y urbanísticos que hasta ahora se han basados casi exclusivamente en el crecimiento ilimitado mediante la transformación de un recurso cada vez más escaso como es el suelo.

El establecimiento de límites al crecimiento urbanístico, dada la gravedad que en algunos casos ha alcanzado la utilización de un urbanismo basado en un crecimiento exponencial, atendidas las voces de alarma y los constantes y contundentes pronunciamientos de todas las instituciones, desde las más altas instancias de las Naciones Unidas hasta la Administración autonómica, pasando por la Administración Estatal y la Comunidad Económica Europea, constituye hoy más una obligación que una opción para el legislador ambiental y territorial. 
No obstante, la clave, como sostiene GUTIÉRREZ COLOMINA ${ }^{37}$ «estará en que en el desarrollo del marco vigente en la ordenación del territorio y en el urbanismo de Andalucía se articule un consenso entre la Administración Autonómica y las entidades locales con los agentes privados, que cambie el hasta ahora desarrollo urbanístico desenfrenado y especulativo por un desarrollo sostenible y que consiga la cuadratura del círculo, el dificil equilibrio de llegar a la sostenibilidad sin detener a su vez el necesario desarrollo económico de nuestra tierra andaluza».

No es fácil que en un mundo como el actual, sobre todo considerando el recorrido histórico de las políticas urbanísticas basadas exclusivamente en la artificialización constante y sin fin del suelo, recurso natural cada vez más escaso, aceptar de buen grado la posibilidad de limitaciones a los crecimientos urbanísticos. Y no parece que puedan abrirse paso sin dificultad políticas de protección del medio ambiente, y dentro de las mismas, de limitaciones, aceptables y aceptadas, a los ritmos de crecimiento urbanístico (incluso al propio crecimiento urbanístico) experimentado en los últimos años, si el ordenamiento normativo territorial y urbanístico no consigue reunir unas mínimas cualidades de congruencia (que las normas resulten coherentes y sin contradicciones), de transparencia (que sean comprensibles y provoquen un sentido de certeza), y que tengan una cierta vocación de continuidad (que proyecten la necesidad y vocación de vigencia y permanencia en el tiempo).

Requiere también el ajuste de la normativa a los elementales principios de legalidad, justicia y seguridad que invariablemente han de estar presentes en un marco normativo tan justificada y marcadamente intervencionista como el de la planificación territorial y urbanística evitando la extensión de la sospecha más o menos fundada de arbitrariedad en la aplicación normativa provocada por la interpretación y reinterpretación constante de la norma general en base a Instrucciones de carácter interno a las que nadie tiene acceso y que hacen posible que una misma Administración, la llamada a ejercer las funciones de control de legalidad en las aprobaciones definitivas del planeamiento municipal, pueda interpretar la norma de distinta forma dependiendo de la provincia en que nos encontremos.

Finalmente, los criterios de protección medioambiental, la introducción y aceptación de las limitaciones a los crecimientos urbanísticos como pautas insoslayables para garantizar la sostenibilidad del planeamiento territorial y urbanístico requieren inevitablemente tomar conciencia de la gravedad del problema por parte de todas las partes interesadas, desde los distintos niveles de la Administración con competencias en la materia (Estatal, Autonómica, Local) hasta el particular, después de todo no de-

37 GUTIÉRREZ COLOMINA, Venancio (2008): 125. 
ja de ser cierto, como defiende VERA JURADO, ${ }^{38}$ que «En España, como en los demás paises comunitarios, la incorporación y el desarrollo de éste ámbito normativo en los últimos ha tenido un gran avance. La cuestión está, no obstante, en la adecuación de las denominadas «condiciones internas de obedicibilidad' 'ilos obligados a cumplirlas están dispuestos y en condiciones de hacerlo?; $y$, en caso negativo ¿la voluntad de los poderes públicos es firme para generar las condiciones necesarias y para hacer cumplir la norma?».

\section{BIBLIOGRAFÍA}

CABRAL GONZÁLEZ-SICILIA, Ángel (2011): «Hacia una más correcta interpretación y una más adecuada aplicación del Plan de Ordenación del territorio de Andalucía». Práctica Urbanística. Número 104. Sección Estudios. Mayo 2011. Editorial LA LEY.

GUTIÉRREZ COLOMINA, Venancio (2008): «POTA I. La Autonomía Local versus discrecionalidad Autonómica en la Ordenación Territorial y Urbanística de Andalucía». Cuadernos de Gestión Pública Local. Instituto Superior de Economía Local (ISEL). Diputación Provincial de Málaga. 2008.

JORDANO FRAGA, Jesús (2009): «Políticas Autonómicas de Medio Ambiente. XIV. Andalucía: Desarrollo sostenible y límites a los crecimientos urbanísticos». Obra colectiva «Observatorio de Políticas Ambientales 2009» coordinada por López Ramón, Fernando. Thomson Reuters Aranzadi. 2009.

MENÉNDEZ REXACH, Ángel (2009): «Urbanismo sostenible y clasificación del suelo: legislación estatal y autonómica». Revista catalana de dret públic. Número 38. 2009.

REGUENCO AGUADO, Luis (2006): «La coordinación de la planificación territorial». Revista Andaluza de Administración Pública. Número 63. 2006.

SÁNCHEZ GOYANES, Enrique (2009): «Ley del Suelo. Comentario sistemático del Texto Refundido de 2008». Editorial LA LEY. Madrid. 2009.

VERA JURADO, Diego J. (2003): «El Medio Ambiente Urbano». Temas de Administración Local Número 78. CEMCI Publicaciones. Granada. 2003.

VERA JURADO, Diego J. (2010): «Los límites del crecimiento: la aplicación de la disposición transitoria cuarta del Real Decreto Legislativo 2/2008, de 20 de junio, por el que se aprueba el Texto Refundido de la Ley de Suelo». Revista de Administración Pública. Número 181. Enero-Abril de 2010.

38 VERA JURADO, Diego J. (2003): «El Medio Ambiente Urbano». Temas de Administración Local Número 78. CEMCI Publicaciones. Granada. 2003, pagina 221. 